\title{
Trajectory mapping of middle atmospheric water vapor by a mini network of NDACC instruments
}

\author{
M. Lainer ${ }^{1}$, N. Kämpfer ${ }^{1}$, B. Tschanz ${ }^{1}$, G. E. Nedoluha ${ }^{2}$, S. Ka ${ }^{3}$, and J. J. Oh ${ }^{3}$ \\ ${ }^{1}$ Institute of Applied Physics, University of Bern, Bern, Switzerland \\ ${ }^{2}$ Remote Sensing Division, Naval Research Laboratory, Washington, DC, USA \\ ${ }^{3}$ Sookmyung Women's University, Seoul 140-742, South Korea \\ Correspondence to: M. Lainer (martin.lainer@iap.unibe.ch)
}

Received: 13 March 2015 - Published in Atmos. Chem. Phys. Discuss.: 29 April 2015

Revised: 22 July 2015 - Accepted: 10 August 2015 - Published: 31 August 2015

\begin{abstract}
The important task to observe the global coverage of middle atmospheric trace gases like water vapor or ozone usually is accomplished by satellites. Climate and atmospheric studies rely upon the knowledge of trace gas distributions throughout the stratosphere and mesosphere. Many of these gases are currently measured from satellites, but it is not clear whether this capability will be maintained in the future. This could lead to a significant knowledge gap of the state of the atmosphere. We explore the possibilities of mapping middle atmospheric water vapor in the Northern Hemisphere by using Lagrangian trajectory calculations and water vapor profile data from a small network of five ground-based microwave radiometers. Four of them are operated within the frame of NDACC (Network for the Detection of Atmospheric Composition Change). Keeping in mind that the instruments are based on different hardware and calibration setups, a height-dependent bias of the retrieved water vapor profiles has to be expected among the microwave radiometers. In order to correct and harmonize the different data sets, the Microwave Limb Sounder (MLS) on the Aura satellite is used to serve as a kind of traveling standard. A domain-averaging TM (trajectory mapping) method is applied which simplifies the subsequent validation of the quality of the trajectory-mapped water vapor distribution towards direct satellite observations. Trajectories are calculated forwards and backwards in time for up to 10 days using 6 hourly meteorological wind analysis fields. Overall, a total of four case studies of trajectory mapping in different meteorological regimes are discussed. One of the case studies takes place during a major sudden stratospheric warming (SSW) accompanied by the polar vortex breakdown; a second takes place
\end{abstract}

after the reformation of stable circulation system. TM cases close to the fall equinox and June solstice event from the year 2012 complete the study, showing the high potential of a network of ground-based remote sensing instruments to synthesize hemispheric maps of water vapor.

\section{Introduction}

Trace gases with a long chemical lifetime can serve as indicators for middle atmospheric dynamics. In our study the focus is directed to middle atmospheric water vapor and its distribution in the Northern Hemisphere (NH). As outlined by Holton and Gettelman (2001), "the bulk of evidence suggests that large-scale slow vertical ascent dominates mass transport across the tropical tropopause, and that slow ascent is required for effective dehydration". A seasonal cycle in the amount of dehydrated air, due to varying temperatures in the UTLS (upper troposphere/lower stratosphere) region, leads to the so called tape recorder effect (Mote et al., 1996). Water vapor in the lower stratosphere of mid-latitudes can originate from moisture plumes above severe thunderstorms during injection processes (Wang, 2003). However chemical reactions like methane oxidation are the major source of middle atmospheric water vapor. These reactions happen in general below an altitude of $50 \mathrm{~km}$ (Brasseur and Solomon, 2006). In higher atmospheric regions the mean lifetime of water vapor due to vertical transport and photochemical mechanisms is similar and on the order of several weeks. As there is no other major chemical source of $\mathrm{H}_{2} \mathrm{O}$ in the mesosphere, it serves as an ideal tracer to study atmospheric dynam- 
ics (Allen et al., 1981; Bevilacqua et al., 1983). Besides its chemical characteristics, water vapor modifies the fluxes of incoming and outgoing radiation in the atmosphere through absorption and emission in the IR band. Another important issue concerns the chemical interaction with ozone. Water vapor in the middle atmosphere is the main source of the $\mathrm{OH}$ radical, which contributes to destruction processes of the UVprotective stratospheric ozone layer. Therefore having information about the distribution of water vapor is of high scientific value.

Apart from "reverse domain filling" (Sutton et al., 1994) and "Kalman filtering" (Julier and Uhlmann, 1997) especially "trajectory mapping" (Morris, 1994; Morris et al., 2000) is used for constructing trace gas maps, validation and climatology studies from irregular (in time and space) distributed profile measurements of either ground- or spacebased instruments. The idea of trajectory mapping is to create synoptic maps by advecting measurements forward and backward in time using a trajectory model that is driven by analyzed model wind fields. Satellite data alone suffer from a poor global horizontal resolution. With the above-mentioned methods, horizontal data gaps can be reduced without spatial interpolation. Several investigations have used this technique in the stratosphere, where $\mathrm{O}_{3}$ and $\mathrm{N}_{2} \mathrm{O} / \mathrm{NO}_{y}$ are of primary importance (Bacmeister et al., 1999; Morris et al., 1995; Liu et al., 2013). Here we will make use of this technique even in the mesosphere and studying water vapor in more detail and its relation to dynamics.

In this study we demonstrate that the trajectory mapping (TM) technique applied to ground-based water vapor profile measurements of a small instrument network operated within the frame of NDACC (Network for the Detection of Atmospheric Composition Change) has the ability to provide adequate information about the horizontal distribution of water vapor, even during fast changing dynamic conditions in the atmosphere (e.g., deformation of the stratospheric polar vortex during a SSW (sudden stratospheric warming) event). A first approach uses a spatial domain-filling TM technique according to Liu et al. (2013). They used the technique for studying global stratospheric ozone climatologies up to $26 \mathrm{~km}$ altitude. The quality of our hemispheric $\mathrm{H}_{2} \mathrm{O}$ volume mixing ratio (VMR) maps depends on how equally the trajectory endpoints are distributed around the hemisphere in a defined pressure layer. By increasing the thickness of a pressure layer, it is possible to enhance the number of TM points and thus the hemispheric data coverage, but the noise in the water vapor maps may increase if vertical $\mathrm{H}_{2} \mathrm{O}$ gradients are large. For the numerical calculation of the 3-dimensional trajectories, it is important to have adequate 3-dimensional wind field data as input. Wind field data sets with large errors may lead to uncontrolled uncertainties of the exact locations of the trajectories. In fact, Stohl and Seibert (1998) found that trajectory position errors in space are much more important than for instance tracer conservation errors. It has been shown that 3-dimensional trajectories in the stratosphere (e.g., as calcu- lated by LAGRANTO) are more accurate in terms of water vapor conservation than for example kinematic isentropic trajectory calculations. In order to keep position errors small, highly accurate meteorological data are needed. Operational analysis data from the European Centre for Medium-Range Weather Forecasts (ECMWF) have been processed to initialize the Lagrangian trajectory model LAGRANTO (Wernli and Davies, 1997). There might be concerns about trajectory qualities above the troposphere in consideration of the question how well high-altitude wind fields can be resolved in global numerical models. Published work, e.g., that of Monge-Sanz et al. (2007), highlights upgrades in the representation of stratospheric winds in operational ECMWF analysis due to better assimilation schemes such as 4D-Var (Rabier et al., 2000). We also explore the suitability of mesospheric trajectory calculations by creating water vapor maps for the $0.13-0.07 \mathrm{hPa}$ pressure range.

The idea to use trajectory mapping of single water vapor profiles by a network of instruments to obtain more information about the horizontal distribution of $\mathrm{H}_{2} \mathrm{O}$ in the middle atmosphere is not new. However, there are only few studies (Flury et al., 2008; Scheiben et al., 2012) that make use of trajectory calculations (e.g., LAGRANTO) to study mesospheric dynamics. Scheiben et al. (2012) applied the TM technique in order to study the effect of a major SSW (sudden stratospheric warming) on the horizontal distribution of water vapor VMR on pressure layers between 0.07-0.14 and $7-14 \mathrm{hPa}$. A simple contrasting juxtaposition between raw (non-unified, non-interpolated) TM maps and pressure layer averaged Aura MLS (Microwave Limb Sounder) measurements has been performed, but a quantitative validation within superposable observations was not applied. In our approach, Aura MLS measurements and the trajectory-mapped data are averaged in 3-dimensional domains; hence one particular mean water vapor VMR value can be assigned to a TM- or MLS-related domain. Because the horizontal and vertical dimension as well as the position of the TM and MLS domains is the same, a more valuable direct comparison is achieved.

A serious problem to overcome is unknown biases between retrieved $\mathrm{H}_{2} \mathrm{O}$ profiles from the mini network of five microwave radiometers. Even though common instrument hardware features were present, we expected a nonnegligible bias in the water vapor VMR between the different instruments. We calculate quasi-seasonal correction factors, depending on the instrument location and height above ground, by making use of NASA's EOS Aura MLS satellite instrument as a kind of traveling standard. Such an approach has been previously used in, e.g., Hocke et al. (2007). A more detailed description of the procedure is outlined in the second part of the paper (Sect. 2.2).

Retrieved water vapor profiles from ground-based observations of a network of five microwave radiometers located over the Northern Hemisphere, where four of them are part of NDACC, are processed. The instruments are MI- 
AWARA (Middle Atmospheric Water Vapor Radiometer) (Deuber and Kämpfer, 2004) at Bern/Zimmerwald (Switzerland), SWARA (Seoul Water Vapor Radiometer) at Seoul (South Korea) (De Wachter et al., 2011), WVMS4 (Water Vapor Millimeter-Wave Spectrometer) (Nedoluha et al., 2011) at Table Mountain (California, USA) and WVMS6 (Nedoluha et al., 2009) at Mauna Loa (Hawaii, USA). Additionally, data from the campaign-based middle atmospheric water vapor radiometer (MIAWARA-C) (Straub et al., 2010), gathered during the Sodankylä campaign at FMI ARC (Arctic Research Centre of Finnish Meteorological Institute) between June 2011 to March 2013, have been incorporated in this TM survey. In the discussion of the results, it will turn out that instrument locations at higher northern latitudes are mandatory to resolve particular polar vortex structures by trajectory mapping.

The paper continues with the description of the trajectory mapping method and construction of the hemispheric maps (Sects. 2.3 and 2.4). In the subsequent Sect. 3 results and validations of four chosen case scenarios for trajectory mapping in 2012 are shown. Different seasonal times are covered to analyze special seasonally caused effects in different dynamical regimes in consideration of an existing middle atmospheric polar vortex. Section 3.3 is dedicated to a major SSW event close to 17 January 2012, a difficult, but interesting test bed for the TM method. A simple error estimation of the trajectory mapping approach is provided in Sect. 3.6. With Sect. 4 a summary and discussion is addressed and a short conclusion is presented in Sect. 5.

\section{Data and methods}

\subsection{NDACC $\mathrm{H}_{2} \mathrm{O}$ microwave radiometer network}

Research stations all over the world contribute to NDACC and provide high-quality long-term measurements of various atmospheric trace gases in a standardized procedure. Identifying trends and changes in the atmospheric composition, understanding their impacts and links to the troposphere and middle atmosphere in the light of climate change are among the most important tasks of this research compound. The NDACC database is commonly used to validate space-based atmospheric measurements (e.g., Froidevaux et al., 1996; Palm et al., 2005; Nedoluha et al., 2007). In our trajectory mapping investigation the different microwave radiometers were cross validated against each other in a first attempt by making use of the double differencing method, first introduced by Revercomb et al. (1988) and applied to either satellite-to-satellite or ground-based-to-ground-based observation validations in the study of Hocke et al. (2007). The five ground-based remote sensing instruments, listed in Table 1, measure the pressure broadened emission line of water vapor molecules at a center frequency of $22.235 \mathrm{GHz}$ (Kämpfer et al., 2012). Water vapor profiles are retrieved from mea- sured spectra by radiative transfer calculations and retrieval techniques such as the optimal estimation method (Rodgers, 2000). Some specifications of the instruments measurement techniques and details about the applied retrieval versions of the $\mathrm{H}_{2} \mathrm{O}$ observations are provided in the next paragraphs.

The microwave radiometer MIAWARA was built in 2002 at the Institute of Applied Physics (University of Bern) and has been continuously operating on the roof of the building for Atmospheric Remote Sensing in Zimmerwald close to Bern since September 2006. The vertical resolution of the instrument varies between $11 \mathrm{~km}$ in the stratosphere and $14 \mathrm{~km}$ in the mesosphere. A former measurement range from approximately 7 to $0.1 \mathrm{hPa}$ (Deuber et al., 2005) could be extended to roughly 10 to $0.02 \mathrm{hPa}$ with instrumental upgrades in spring 2007. An acousto-optical spectrometer (AOS) was replaced by a digital FFT (fast Fourier transform) spectrometer that improved the spectral resolution from 600 to $61 \mathrm{kHz}$. Tropospheric opacity due to weather conditions can affect the temporal resolution. With low optical depths in the sensitive frequency region of the radiometer during dry and cold tropospheric conditions, temporal resolutions on the order of few hours are achievable. But temporal resolutions up to $12 \mathrm{~h}$ or more are likely when warm and humid periods occur. The MIAWARA profile retrievals used for the trajectory mapping investigation have a constant time resolution (integration time) of $12 \mathrm{~h}$, a total bandwidth of $225 \mathrm{MHz}$ and are processed with Aura MLS v3.3 observation data to initialize pressure, temperature and geopotential height as PTZ source.

The campaign-based version of MIAWARA, MIAWARAC (Straub et al., 2010), was operated in Sodankylä at FMI ARC $\left(67.37^{\circ} \mathrm{N} / 26.63^{\circ} \mathrm{E}\right.$, Finland) from June 2011 to March 2013 with practically no interruptions. Because of an almost doubled FFT spectrometer resolution of $30.5 \mathrm{kHz}$ the upper measurement limit reaches $0.015 \mathrm{hPa}(78 \mathrm{~km})$. At best, a lower measurement limit of $35 \mathrm{~km} \approx 7 \mathrm{hPa}$ can be achieved. Vertical resolution varies from 12 to $15 \mathrm{~km}$ (Tschanz et al., 2013). In this study we process a MIAWARA-C retrieval version with fixed temporal resolution of $12 \mathrm{~h}$, a bandwidth of $80 \mathrm{MHz}$ and Aura MLS v3.3 data as PTZ source. Even though temporal integrations of less than $2 \mathrm{~h}$ are feasible for retrieval calculations, we prefer a constant $12 \mathrm{~h}$ integration time due to better signal to noise ratios.

The microwave radiometer SWARA was developed, like MIAWARA and MIAWARA-C, at the Institute of Applied Physics at the University of Bern and has been operational since October 2006 at the Sookmyung Women's University of Seoul in South Korea (De Wachter et al., 2011). SWARA is in principle a copy of MIAWARA and the same specifications apply. However, as the wings of the spectrum are affected by baseline ripples a retrieval of water vapor at altitudes below $38 \mathrm{~km}$ with a reasonable (>60\%) measurement response is limited (50 $\mathrm{MHz}$ retrieval bandwidth). For that reason data below $4 \mathrm{hPa}$ are not used. The SWARA $\mathrm{H}_{2} \mathrm{O}$ profiles for TM have a fixed temporal resolution with an integration time of the calibrated spectrum (Level 1 data) of 
Table 1. Locations of middle atmospheric water vapor radiometers used in this study with the geolocation and operational period of each station (OP). MIAWARA-C is a campaign instrument.

\begin{tabular}{lrrrl}
\hline Station/instrument name & Latitude $\left({ }^{\circ} \mathrm{N}\right)$ & Longitude $\left({ }^{\circ} \mathrm{E}\right)$ & Altitude $(\mathrm{m})$ & OP $(\mathrm{yr})$ \\
\hline Bern/MIAWARA & 46.88 & 7.46 & 907 & since 2002 \\
Seoul/SWARA & 37.54 & 127 & 52 & since 2006 \\
Mauna Loa/WVMS6 & 19.5 & -155.4 & 3394 & since 1996 \\
Table Mountain/WVMS4 & 34.4 & -117.7 & 2282 & since 1993 \\
Sodankylä/MIAWARA-C & 67.37 & 26.63 & 190 & $2011-2013$ \\
\hline
\end{tabular}

$24 \mathrm{~h}$. The same PTZ information source (Aura MLS v3.3) as for MIAWARA applies.

Two further instruments from NDACC are used. Specifically, we make use of measurements from the ground-based Water Vapor Millimeter-wave Spectrometer (WVMS6) at Mauna Loa (HI, USA), and from WVMS4 at Table Mountain (CA, USA). In this study we will make use of data from both of these instruments up to $68 \mathrm{~km}(0.05 \mathrm{hPa})$. Nedoluha et al. (2013) showed that retrievals from the WVMS4 instrument down to $26 \mathrm{~km}$ were in good agreement with satellite measurements, and we will use these retrievals down to $10 \mathrm{hPa}$. The WVMS6 instrument now continues the water vapor record at Mauna Loa (since March 2011) previously recorded by the WVMS3 instrument. WVMS6 retrievals have not been validated below $40 \mathrm{~km}$, and we will restrict their use here to the range $5-0.05 \mathrm{hPa}$. These instruments have a vertical resolution of around $15 \mathrm{~km}$ and a measurement error of about $9 \%$. The WVMS data are provided in the downloadable NDACC files (NASA Ames Format for Data Exchange) as daily averages between midnight and midnight in local time and are linked to an altitude grid with a spacing of $2 \mathrm{~km}$. Dependent on the altitude region, temperature and pressure for the retrieval calculations come either from a MLS climatology (upper stratosphere and mesosphere), NCEP (National Centers for Environmental Prediction) data (lower stratosphere) or MSIS (Mass Spectrometer Incoherent Scatter Radar) model (thermosphere).

In principle, a 6-hour temporal resolution of the profile data (to fit the time spacing of the meteorological input fields of the ECMWF analysis data) would be optimal for trajectory mapping in the proper sense of unifying the data sets with fewer interpolation steps. Due to different locations and altitudes of the instruments (different climatological conditions) such a uniform and high temporal data resolution is not realizable. To resolve fast changing water vapor distributions associated with polar vortex movements adequately by trajectory mapping, at least a $24 \mathrm{~h}$ temporal resolution of the retrieved $\mathrm{H}_{2} \mathrm{O}$ profiles should be used.

The vertical $\mathrm{H}_{2} \mathrm{O}$ a priori profile information needed in the retrieval calculations of the instruments MIAWARA, MIAWARA-C and SWARA is based on the same climatology. The a priori is taken from a monthly mean zonal mean climatology using Aura MLS v2.2 data between 2004 and
2008. The NDACC retrievals of the instruments in Hawaii (WVMS6) and on Table Mountain (WVMS4) are all also run with an Aura MLS based climatology as a priori. Particularly, it is based on v3.3 data taken from August 2004 to March 2011 within $\pm 2^{\circ}$ latitude and $\pm 30^{\circ}$ longitude of each observation site. For each day of the year, the data are averaged over \pm 5 days.

In the following more details about the a priori contribution or measurement response of the individual instruments are given. Different features observed in the measurement responses between $0.05-10 \mathrm{hPa}$ resulted in adjusted data omissions to keep the a priori influence on the $\mathrm{H}_{2} \mathrm{O}$ retrievals small. This is of special importance since the trajectorymapped data are compared to Aura MLS for validation. At the Mauna Loa observation site (WVMS6) the validation of the data variations down into the lower stratosphere is still missing, which is why it is grayed out in Figs. 1 and 2 and data from below $5 \mathrm{hPa}$ are not used in the four TM case studies. The instruments providing measurements down to $10 \mathrm{hPa}$ (MIAWARA and WVMS4) have a priori contributions of less than $25 \%$ (20\% for WVMS4) at this level. In case of SWARA and MIAWARA-C there is a transition from 2 to $4 \mathrm{hPa}$, where the a priori contribution drops from $\sim 50 \%$ (at $4 \mathrm{hPa}$ ) to $\sim 20 \%$ (at $2 \mathrm{hPa}$ ). At higher altitudes the measurement responses are widespread above $80 \%$, considering data from 2012. Accordingly, data from SWARA and MIAWARA-C are only used between $0.05-4 \mathrm{hPa}$ as indicated in Figs. 1 and 2. It is stated that SWARA $\mathrm{H}_{2} \mathrm{O}$ retrievals sometimes show a priori contributions up to $40 \%$ between $0.05-0.3 \mathrm{hPa}$ in the summer months, which is tolerable.

We conclude that the fact that Aura MLS $\mathrm{H}_{2} \mathrm{O}$ climatologies serve as a priori profiles in the five ground-based instrument retrievals, which are compared to MLS data after application of our TM method, is of minor relevance as we do account for bad profile sections and therefore confine the comparison of TM data where the contribution of the a priori is most of the time low.

\subsection{Data harmonization - satellites as traveling standard}

Although several significant studies have been performed to validate ground-based water vapor microwave radiometer instruments and to find biases relative to space-borne mea- 

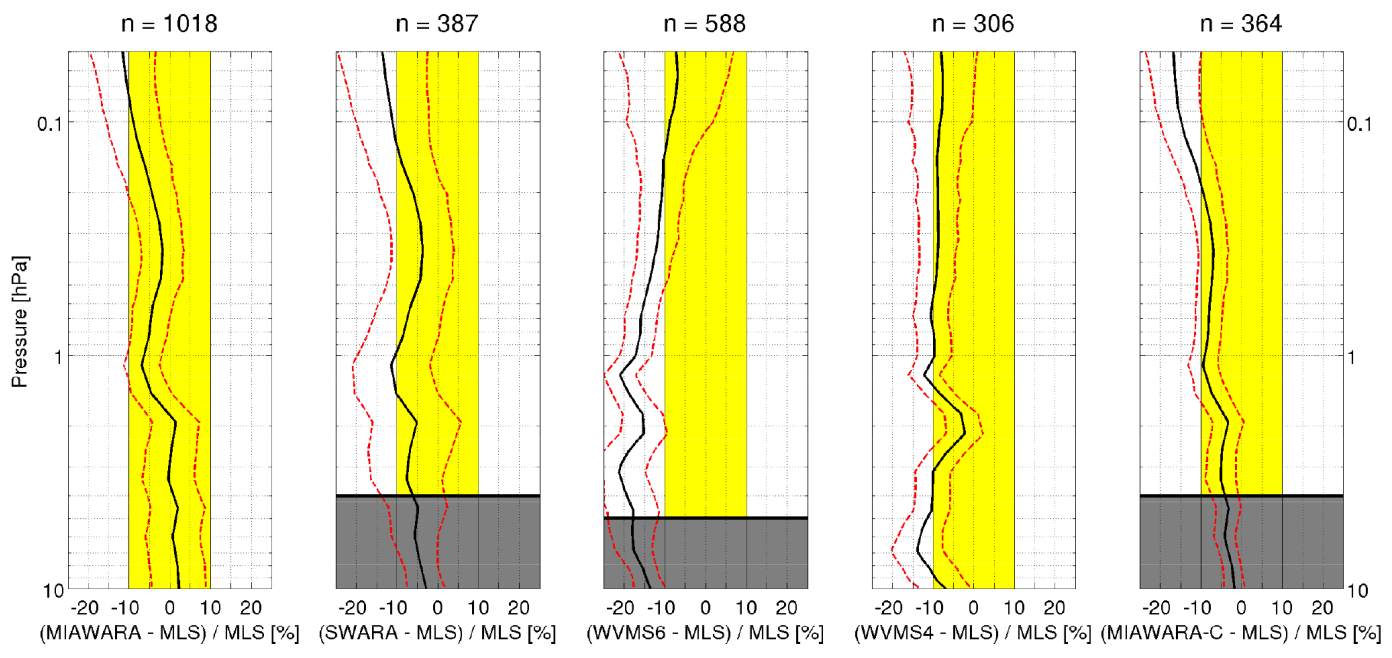

Figure 1. Summer season (NH) mean relative differences (black lines) of the water vapor difference profiles between five ground-based water vapor radiometer stations (panels from left to right: (1) Bern, (2) Seoul, (3) Mauna Loa, (4) Table Mountain, (5) Sodankylä) and Aura MLS. The mean difference profiles are calculated from measurements in the period from August 2010 to September 2014, considering the following months: April, May, June, July, August, September. The number of individual profiles considered per instrument is represented by $n$. Dashed red lines show the $\mathrm{SD} \pm \sigma$ of all $n$ differences and the yellow stripes depict the $\pm 10 \%$ areas. Data below pressure levels indicated by the horizontal black lines (grey areas) were not used due to overly high a priori contributions in the water vapor retrievals.
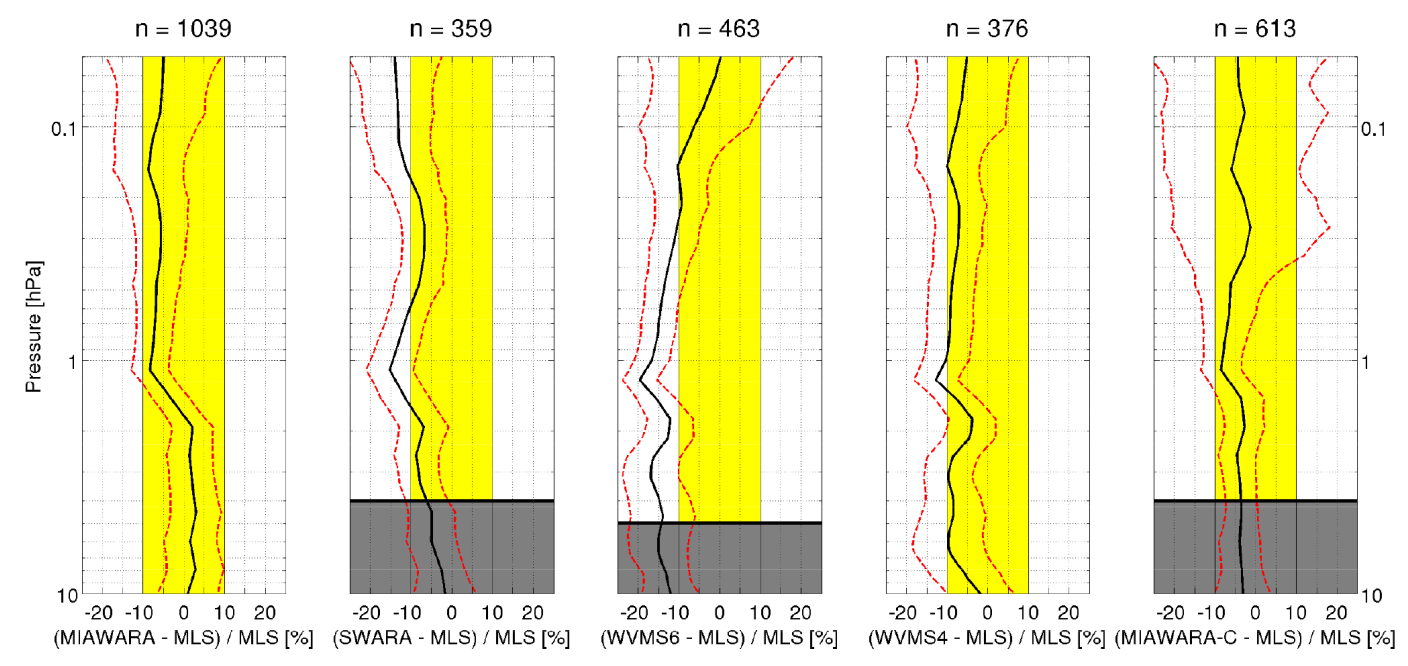

Figure 2. Same as Fig. 1 but for the winter season (NH), considering the following months in the period from August 2010 to September 2014: October, November, December, January, February, March.

surements (Haefele et al., 2009; De Wachter et al., 2011; Nedoluha et al., 2013; Tschanz et al., 2013), a harmonization is still strongly needed for combining middle atmospheric $\mathrm{H}_{2} \mathrm{O}$ VMR measurements from different instruments in view of our specific purpose.

The water vapor product from Aura MLS is retrieved from radiance emission measurements near a center frequency of $183 \mathrm{GHz}$ as outlined by Lambert et al. (2007). The gathered data are very valuable to our trajectory mapping investigation because of the near-global $\left(82^{\circ} \mathrm{S}\right.$ to $\left.82^{\circ} \mathrm{N}\right)$ coverage and daily observations above all five ground-based microwave radiometer locations (see Table 1) within our defined horizontal coincident displacement criteria of $800 \mathrm{~km}(\mathrm{E} / \mathrm{W})$ $\times 400 \mathrm{~km}(\mathrm{~N} / \mathrm{S})$. Besides the water vapor product we also refer to temperature observations when we discuss the January 2012 sudden stratospheric warming event in Sect. 3.3. In this study we use the v3.3 data product which shows substantial improvements compared to the previous v2.2 product by getting rid of small scale vertical variations in the water vapor retrievals (Livesey et al., 2011). The whole vertical range is between 316 and $0.002 \mathrm{hPa}$, and the accuracy varies roughly between 4 and $11 \%$ in the $10-0.01 \mathrm{hPa}$ pressure 
regime. A 3.2 to $10 \mathrm{~km}$ vertical resolution again in-between $10-0.01 \mathrm{hPa}$ goes along with a spatial wide horizontal resolution in the range of 300 to $680 \mathrm{~km}$. We use MLS data if according to the data quality documentation (Livesey et al., 2011) quality thresholds are preserved within the addressed vertical range.

The double differencing method is a useful technique in the case of a two-instrument network to obtain the bias between instruments by making use of one traveling satellite, which observes the same air columns above the groundbased observation sites. A larger network, such as ours, requires a different strategy. Mean relative difference profiles are calculated for every single ground-based instrument to Aura MLS in a quasi-seasonal (6-month periods) manner to take the bias into account. All individual profiles are linearly interpolated in logarithmic pressure to cover the same vertical extent $(10-0.05 \mathrm{hPa})$ with the identical number of 1000 grid points, which serve later as trajectory starting points.

The mean relative difference profiles (Figs. 1 and 2) reveal that nearly all relative $\mathrm{H}_{2} \mathrm{O}$ deviations are within $\pm 15 \%$. An exception is WVMS6 located in Hawaii with deviations exceeding $15 \%$. As the yellow bands indicate, the instruments at Bern, Seoul, Table Mountain and Sodankylä have biases of less than $10 \%$ to MLS in most of the regarded altitude ranges. During both the April to September and the October to March periods, the mean difference water vapor profiles of all measurement sites show an abrupt increase of 5-10\% difference to MLS from around 2 to $1 \mathrm{hPa}$. Despite small variations in the seasonal behavior of the SD (standard deviation) $\sigma$ the profile structures stay comparable. The largest uncertainty $(\sigma \approx 20 \%)$ in the mean difference can be assigned to MIAWARA-C observations above the polar winter stratopause. Several hundreds of profiles are processed in the time period from August 2010 until September 2014 to calculate the mean difference $\mathrm{H}_{2} \mathrm{O}$ profiles, serving as height-dependent correction factors to harmonize the trajectory-mapped $\mathrm{H}_{2} \mathrm{O}$ VMR values during the synthesis of hemispheric maps (see Sect. 2.4).

In summary, all averaged ground-based measurements of the five instrument locations result in a negative bias to Aura MLS throughout all of the studied altitudes; i.e., the water vapor mixing ratio measured by MLS is consistently higher than that measured by ground-based instruments.

\subsection{The trajectory model}

Numerical trajectory simulations in the middle atmosphere were performed with LAGRANTO (Wernli and Davies, 1997), a software tool consisting of UNIX shell scripts and FORTRAN programs to analyze Lagrangian aspects of atmospheric phenomena. The program requires a time series of 3-dimensional wind fields in NetCDF files. Possible error sources are interpolation steps and uncertainties in meteorological input data. Interpolation errors develop when the model wind field from the model time and grid resolu- tion is interpolated to an actual trajectory location in the 4dimensional continuum. With respect to the true atmospheric state, errors will remain in the initial model conditions, limiting the accuracy of the wind fields.

The 3-dimensional wind vector data are from the European Centre for Medium-Range Weather Forecasts (ECMWF). A daily model run (cycle 37R3 - T1279) provides meteorological data sets on a 6 hourly spaced time interval from midnight to midnight. The operational model analysis provides 91 vertical model levels from the surface up to $0.02 \mathrm{hPa}$. A regular latitude/longitude grid with a resolution of $1.125^{\circ} \times 1.125^{\circ}$ is used for the horizontal plane. Scheiben et al. (2012) created middle atmospheric $\mathrm{H}_{2} \mathrm{O}$ trajectory maps of synoptic scale also with 6 hourly ECMWF data, but at a higher horizontal resolution of $0.5^{\circ} \times 0.5^{\circ}$. Our results suggest that the horizontal model resolution is not a key factor and more accurate trajectory maps can be produced with a lower LAT/LON resolution, even during dynamical extreme events. In general, errors connected to wind field interpolations are of significant relevance. According to Stohl et al. (1995) errors (e.g., gridded ECMWF model variables) related to spatial interpolations are much smaller than those related to temporal interpolations, which are the primary limiting factor of the accuracy of trajectories. The interpolation of the horizontal wind components is less error-prone than for the vertical motion $w$. Stohl et al. (1995) described in their study that a doubling of the temporal model resolution from 3 to $6 \mathrm{~h}$ can result in up to $40 \%$ mean relative interpolation errors of the vertical wind component.

Most modern trajectory models use the second-order iterative Petterssen scheme (Petterssen, 1940) in their dynamical core for solving the trajectory (Eq. 1).

$\frac{\mathrm{D} \boldsymbol{x}}{\mathrm{D} t}=\boldsymbol{u}(\boldsymbol{x}, t)$.

The Petterssen scheme (Eq. 2) has a truncation (numerical dispersion) error proportional to $\Delta t^{2}$ where $\Delta t$ is the numerical time step. This error occurs, when higher order terms in the Taylor expansion are neglected. In Eq. (2) $x_{0}$ describes the initial position vector, whereas $\boldsymbol{x}_{1}, \boldsymbol{x}_{n}$ correspond to the positions after 1 respectively $n$ iteration steps.

$x_{1}=x_{0}+\Delta t \cdot \boldsymbol{u}\left(x_{0}, t\right)$
$\boldsymbol{x}_{n}=\boldsymbol{x}_{0}+\frac{1}{2} \Delta t\left[\boldsymbol{u}\left(\boldsymbol{x}_{0}, t\right)+\boldsymbol{u}\left(\boldsymbol{x}_{n-1}, t+\Delta t\right)\right]$.

The external velocity field $\boldsymbol{u}(\boldsymbol{x}, t)$ and a second-order semiimplicit discretization in time and space are needed to compute the future trajectory position. If the Courant-FriedrichsLewy (CFL) criterion $(c=\boldsymbol{u} \cdot \Delta t / \Delta \boldsymbol{x}<1)$ is fulfilled, the computed solution is numerically convergent. Obviously, the Courant number $c$ depends on the numerical time step $\Delta t$ and the wind field variable $\boldsymbol{u}$. Earlier simulations performed by Scheiben et al. (2012) revealed that a time step of around $300 \mathrm{~s}$ is short enough for calculations with the ECMWF operational data set. There, observations of two ground-based 
water vapor microwave radiometers were used for trajectory mapping and it was possible to find the approximate location and extension of the stratospheric polar vortex with the obtained $\mathrm{H}_{2} \mathrm{O}$ distribution. But irregularities in the measurements and a sparsely distributed observation network could not match the quality of synoptic maps from satellite observations.

The applied trajectory mapping method uses the following assumption. It is assumed that an air parcel's water vapor volume mixing ratio stays constant while moving along a 3-dimensional 10-day trajectory. Hence, turbulent mixing, photolysis, chemical reactions and phase changes of $\mathrm{H}_{2} \mathrm{O}$ are not taken into account. Schoeberl and Sparling (1995) as well as Morris et al. (1995) already showed with trajectory studies that a time period of 10 days for forward or backward trajectories is a reasonable timescale in the stratosphere. We will make use of 10-day trajectories up to $0.05 \mathrm{hPa}$.

\subsection{Trajectory mapping - synthesis of hemispheric $\mathrm{H}_{2} \mathrm{O}$ maps}

LAGRANTO initializes trajectory calculations with starting points of an air parcel in a latitude, longitude and pressure level coordinate system. To generate synoptic maps with trajectory mapping, the definition of a pressure layer with a certain thickness $\Delta p$ is required. In order to increase the number of trajectory arrival points from instrument observations (trajectory starting points) inside a defined pressure layer, different implementations such as increasing the TM pressure layer thickness, the number of vertical trajectory starting points with interpolation or an extended instrument network might be considered. Keeping in mind that a maximal vertical measurement resolution of $\sim 10 \mathrm{~km}$ is realistic, the number of vertical starting points can only be enlarged by interpolation of the water vapor profiles. The largest uncertainties during the LAGRANTO calculations are likely arising from the interpolation of the vertical wind component. It is important that the starting points of the trajectory calculations in LAGRANTO are within the ECMWF vertical model grid (91 levels). Otherwise the interpolations to the starting point positions are impossible. Horizontal interpolations of the ECMWF wind field data to the actual trajectory positions are bilinear; vertical ones linear with pressure and time interpolations are also performed linearly.

The water vapor profiles of the instrument network are interpolated to a pressure grid with a logarithmic equispaced subdivision of 1000 pressure levels between $10-0.05 \mathrm{hPa}$. This is equal to $\mathrm{a} \sim 37 \mathrm{~m}$ vertical grid point spacing. According to instrument features and retrieval versions different altitude data cut-off limits in the stratosphere are used as described in Sect. 2.1 and illustrated with the bias correction plots of Figs. 1 and 2. The interpolated volume mixing ratios on the grid points are used to create raw trajectory maps. Altogether 20 days of water vapor profile measurements from each instrument are taken. As the temporal resolution varies between 12 and $24 \mathrm{~h}$, one or two profiles per day are obtained accordingly. A mean time is assigned to each profile, which results in a $\mathrm{H}_{2} \mathrm{O}$ profile time series. Because the wind field data of the ECMWF model that go into LAGRANTO have temporal resolution of $6 \mathrm{~h}$, we further temporally interpolate the prior pressure interpolated profile time series of every single radiometer onto the time grid of the ECMWF model.

Now trajectories can be calculated every $6 \mathrm{~h}$ starting from every grid point of the processed profiles. For 20 days and with four profiles per day plus the initial profile on the TM target time $(4 \cdot 20)+1=81$ profiles are created over one ground-based instrument location. If measurement gaps extend over more than $96 \mathrm{~h}$ the mixing ratios of the corresponding interpolated water vapor profiles are disregarded. The remaining data are needed to synthesize a trajectory map at the center of the 20-day time period of considered measurements. Forward trajectories are calculated for the first 40 water vapor profiles of each measurement site and the corresponding backward trajectories for the last 40 profiles. The profile number 41 is already at the right position in time for the trajectory map. If all trajectories are summed for a 20 day period and five ground-based stations, we count $4 \times 10^{5}$ trajectories.

The volume mixing ratios from the grid points of the profiles belonging to the trajectory start points were assigned to the new calculated trajectory end points, assuming that the $\mathrm{H}_{2} \mathrm{O}$ mixing ratio stays constant. While we are calculating 3-dimensional paths through the atmosphere, the trajectory end points can rise or sink in altitude. A simple filtering is done to separate out the mixing ratios of points within the different defined pressure layers $(12-8,3.5-2.5,1.3-0.7$ and 0.13-0.07 hPa) in order to get a simple raw TM map, consisting of single points in 3-dimensional space, at 12:00 UTC. A problem with a thick pressure layer can be that a less homogeneous trajectory map is produced if large vertical gradients in $\mathrm{H}_{2} \mathrm{O}$ exist. The trajectory origin of the single points can be outside the previous defined pressure layers due to rising or descending trajectories. Later in Sect. 3 we only refer to the middle of the pressure layers $(10,3,1$ and $0.1 \mathrm{hPa})$. The chosen layers ensure that at least one MLS measurement on the native vertical resolution is situated at or close to the middle of a layer.

On the basis of raw trajectory maps alone, a quantitative verification to other measurements would be difficult. With the idea of uniquely defined 3-dimensional domains, where the trajectory-mapped $\mathrm{H}_{2} \mathrm{O}$ VMR data are averaged, a proper solution for following verifications was found. Depending on whether domains are in the stratosphere or mesosphere, the horizontal expansion varies from $2.5^{\circ} \times 2.5^{\circ}$ to $5^{\circ} \times 5^{\circ}(\mathrm{LAT} \times \mathrm{LON})$ in the domain-averaged TM maps. With a doubling of the horizontal domain-averaging size at the stratopause region and above, we accounted for the altitude increasing uncertainty of middle atmospheric ECMWF wind fields by an increased blurring of trajectory endpoint positions. The vertical extent is in agreement with the previous 
mentioned pressure layer thickness. The horizontal scale of the domain averaging is in general smaller than the characteristic correlation length of water vapor in the middle atmosphere. A short time series (several months in 2012) of MIAWARA water vapor profiles has been processed with an auto-correlation function (ACF) according to Reinsel et al. (1994) in order to compute characteristic correlation times. A timescale between 1-3 days is necessary to decrease the correlation coefficient by a factor of $e$. Assuming a mean horizontal wind velocity of $10 \mathrm{~m} \mathrm{~s}^{-1}$ a correlation length scale on the order of 860-2600 km results. Liu et al. (2009) came up with similar correlation time (length) scales for ozone in the stratosphere with 2-6 days (1000-2000 km).

Due to averaging TM data inside the domains, some noise in the water vapor maps is reduced. On the other hand, as an example, a vertical averaging of $\mathrm{H}_{2} \mathrm{O}$ within the defined domains can produce a bias due to the fact that a point $\mathrm{A}$, say at $3.5 \mathrm{hPa}$, will have a mixing ratio lower than point $\mathrm{B}$, say at $2.5 \mathrm{hPa}$, just because it is lower in the atmosphere. We correct for most of the bias in this by subtracting the a priori vertical profile from the measurements prior to the trajectory calculations and then adding the a priori for the middle of the pressure layers at the end.

In addition, we plot the edges of the polar vortex at the lower and upper limit of the current pressure layer. We adapt the definition and calculation of the vortex edge from Scheiben et al. (2012), which is effective from 10 to $0.01 \mathrm{hPa}$ and uses the highest absolute wind speed along a geopotential height (GPH) contour (averaged) together with a minimal border length of $15 \times 10^{3} \mathrm{~km}$ on a pressure level. Additionally the GPH contour has to enclose a low-pressure system and must be everywhere north of $15^{\circ} \mathrm{N}$.

For all four TM case studies related domain-averaged Aura MLS water vapor maps were produced for comparison. The domains in the MLS observation plots coincide with the TM domains, because of their global definition. Aura MLS measurements of a whole hemisphere cannot show one particular point in time. To gather all information needed along the orbit tracks, 1 day passes by. We account for the different time offsets between trajectory-mapped data and Aura MLS measurements by linearly interpolating the domain-averaged MLS data along the orbit track onto the trajectory mapping target time by using the measurements of the previous and the following day. The domain sizes of MLS and TM are identical. Incidentally matching domains and their $\mathrm{H}_{2} \mathrm{O}$ volume mixing ratio $Q$ are directly compared in relative difference maps (e.g., fourth columns in Figs. 3 to 5 and 7). The relative difference $D_{\text {rel }}$ is calculated according the following Eq. (3).

$D_{\mathrm{rel}}=\frac{Q_{\mathrm{TM}}-Q_{\mathrm{MLS}}}{Q_{\mathrm{MLS}}}$.

\section{Results}

In this section we present our results for a total of four $\mathrm{H}_{2} \mathrm{O}$ trajectory mapping case studies in 2012. We abbreviate the case studies with capital letters from A to D. The days of two case scenarios (A and D) belong to northern hemispheric winter time, where polar vortex structures were formed and non-zonal water vapor distribution occurred (Sects. 3.1 and 3.3). With case study D (17 January 2012), one particular selected date related to a sudden stratospheric warming is included, where the zonal mean temperature at $10 \mathrm{hPa}$ increased by more than $25 \mathrm{~K}$ just north of $60^{\circ} \mathrm{N}$ in a few days and the prevailing westerlies changed direction to become easterlies. All conditions of a major SSW (cf. Schoeberl, 1978) were fulfilled. An idealized ECMWF wind modification case study $\mathrm{D}^{\star}$ is included, trying to improve trajectory positions in the mesosphere on 17 January 2012.

With case B, a trajectory mapping day on the fall equinox of 2012 (9 September) is investigated. Performing trajectory calculations around the equinox is particularly interesting because the zonal wind direction in the stratosphere and mesosphere reverses to the winter westerlies and the polar vortex forms again.

Case study C in Sect. 3.2 shows the performance of TM on a northern hemispheric summer day (21 June 2012) without a polar vortex. The transport of atmospheric constituents over the ground-based instrument locations is mainly governed by zonal winds. In summer the prevailing advection route is from east to west in the stratosphere and mesosphere.

\subsection{TM in polar vortex regimes - case study A and B}

Figure 3 shows TM case study A with all investigated altitude ranges (from top to bottom), as will be the case in Figs. 4, 5 and 7 . The positions of the polar vortex edges within the altitude range of the respective plot are indicated by solid (lower altitude limits) and dashed (upper altitude limits) black lines. At the vortex edges high gradients in potential vorticity are present and the mean zonal wind speeds become fastest. A typical just slightly disturbed polar vortex pattern centered around the North Pole is visible in the stratosphere. Looking at the relative positions of the groundbased observatories (black circles) with respect to the vortex edge at that time (28 February 2012, 12:00 UTC), it is obvious that MIAWARA-C (Sodankylä) is situated inside the vortex, whereas the four other instruments (Table 1) are outside. Referred to the $3 \mathrm{hPa}$ pressure level, Bern and Table Mountain are rather close to the comma-shaped vortex edge and Seoul lies furthest away. The vertical displacement of the polar vortex is marginal and mostly on the order of one domain size $\left(2.5^{\circ} / 5^{\circ}\right)$. Isentropic tracers like water vapor tend to stay trapped inside the polar vortex system, which has a limited air-mass mixing across the edge (Paparella et al., 1997). Trajectory-mapped $\mathrm{H}_{2} \mathrm{O}$ on $3 \mathrm{hPa}$ is found to be approximately $1 \mathrm{ppm}$ lower inside the plotted stratospheric 

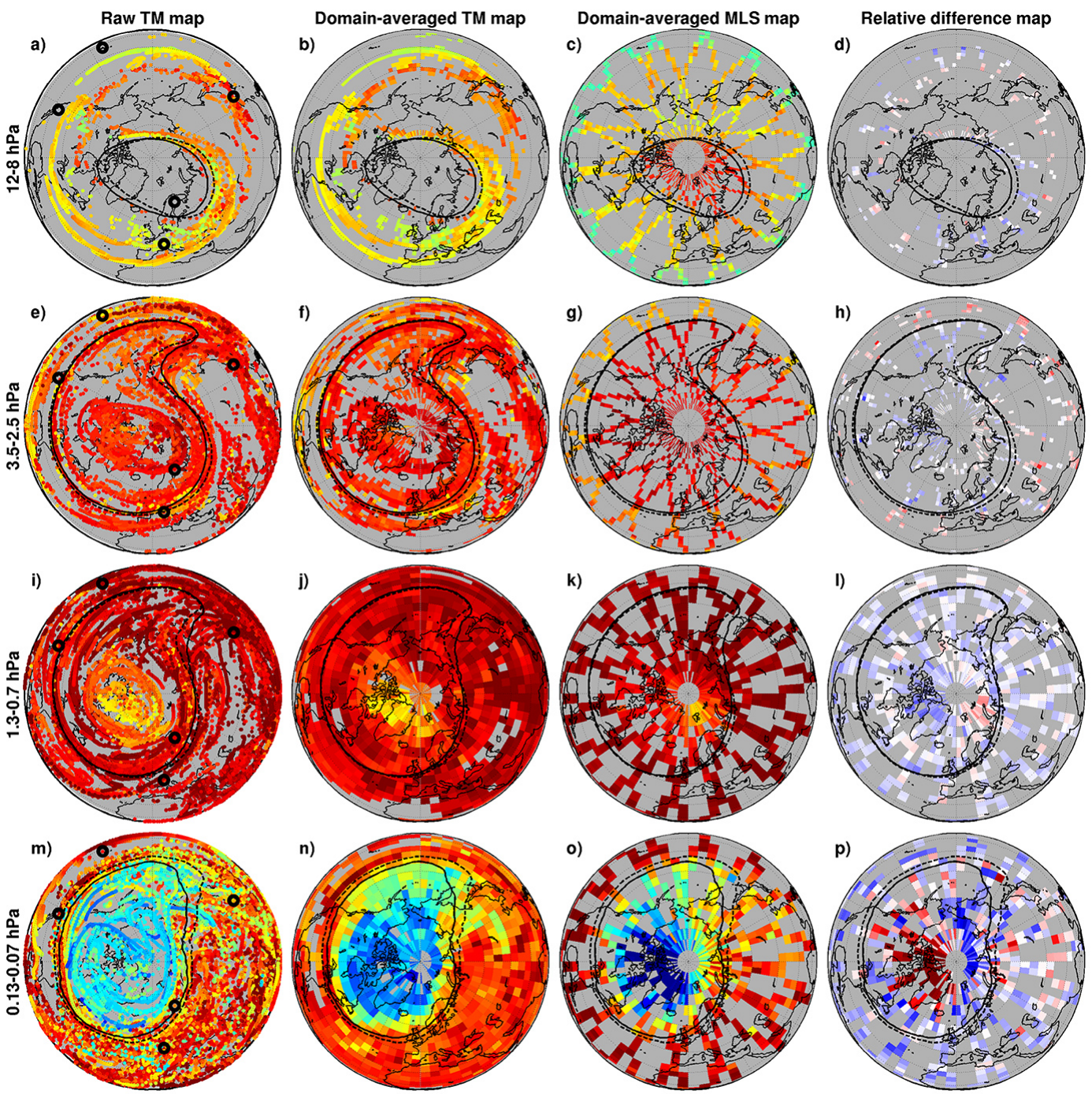

$\mathrm{H}_{2} \mathrm{O}$ VMR [ppm]

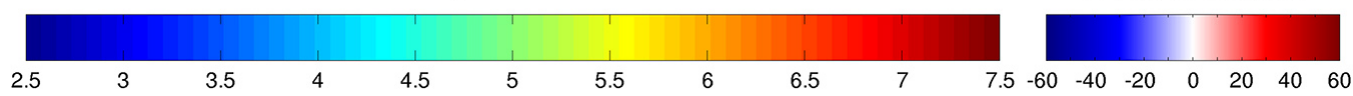

Figure 3. Case A: stratospheric $\mathrm{H}_{2} \mathrm{O}$ VMR [ppm] within 12 to $8 \mathrm{hPa}(\mathbf{a}-\mathbf{c}), 3.5$ to $2.5 \mathrm{hPa}(\mathbf{e}-\mathbf{g})$, respectively mesospheric $\mathrm{H}_{2} \mathrm{O}$ VMR within 1.3 to $0.7 \mathrm{hPa}(\mathbf{i}-\mathbf{k}), 0.13$ to $0.07 \mathrm{hPa}(\mathbf{m}-\mathbf{0})$ on 28 February 2012 12:00 UTC. Harmonized trajectory-mapped ground-based measurements from five stations (black circles) corresponding to Bern, Seoul, Hawaii, Table Mountain and Sodankylä are displayed in raw (first column), with $2.5^{\circ} \times 2.5^{\circ}$ (first and second row) or $5^{\circ} \times 5^{\circ}$ (third and fourth row) domain-averaged format (second column). Pressure layer and domain-averaged Aura MLS v3.3 observations are shown in the third column. Relative difference maps of coincident domains between TM and Aura MLS data are shown in the fourth column. All charts indicate the position and vertical displacement of the polar vortex edge within the given pressure layers by the solid black (upper $p$ limit) and dashed black (lower $p$ limit) lines. Grey areas indicate no data coverage.

vortex compared to Aura MLS water vapor maps. The vortex edge can qualitatively be determined from the TM trace gas distribution on $3 \mathrm{hPa}$ and from the data gap shape on $10 \mathrm{hPa}$, but not as clearly as from Aura MLS $\mathrm{H}_{2} \mathrm{O}$ observations. The data gap inside the $10 \mathrm{hPa}$ vortex is due to the cut-off criterion for the MIAWARA-C profiles with an overly high a priori contribution. More than one observing site inside such a large and isolated quasi-zonal stratospheric wind systems would be advantageous in determining more precisely borders of air masses.

The nature of satellite observations has the advantage of more uniformly covered measurements around the globe which TM sometimes cannot provide; rather, randomly spread data points and various data gap sizes occur, especially in the stratosphere. For instance, a larger $\mathrm{H}_{2} \mathrm{O}$ data gap (beside the vortex area) extends between Alaska and 

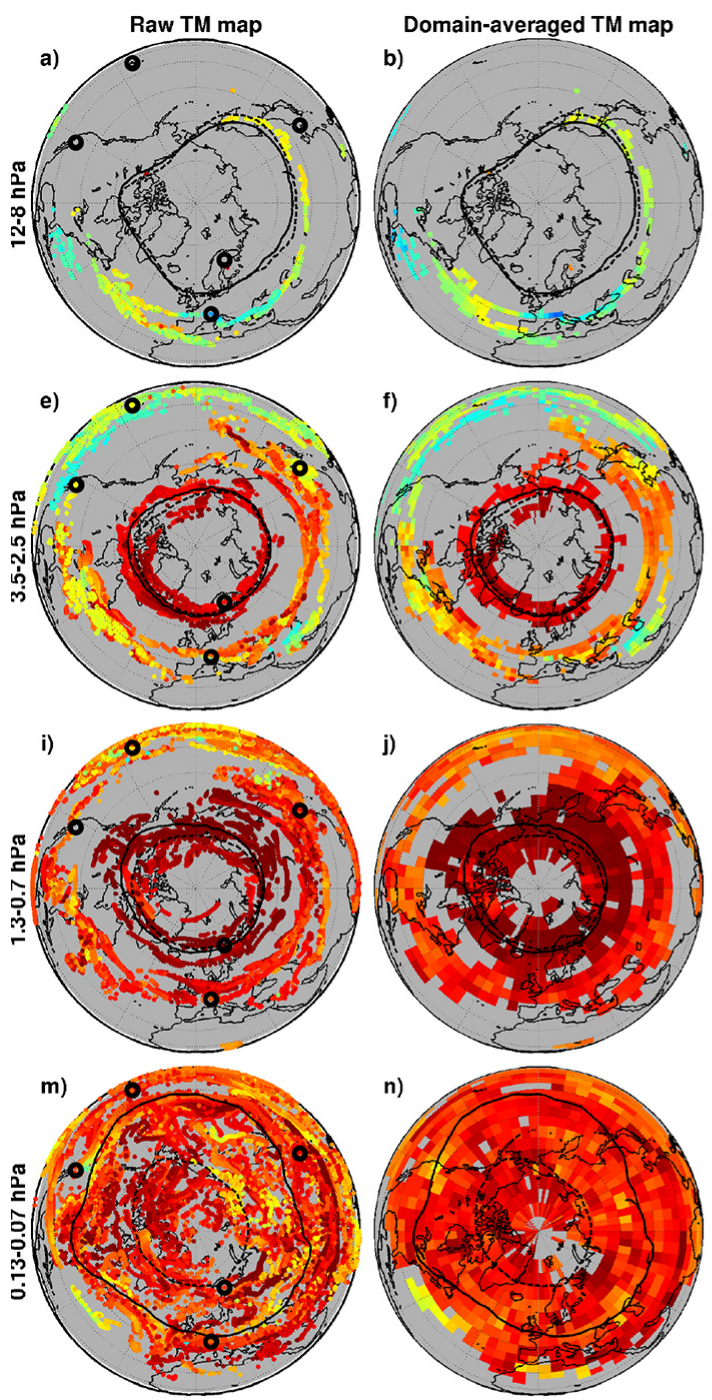

$\mathrm{H}_{2} \mathrm{O}$ VMR [ppm]
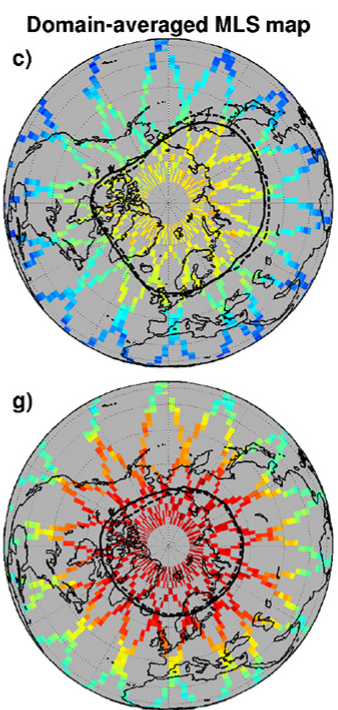

k)

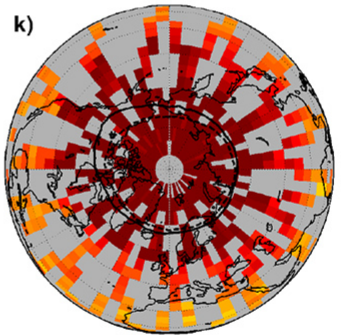

o)
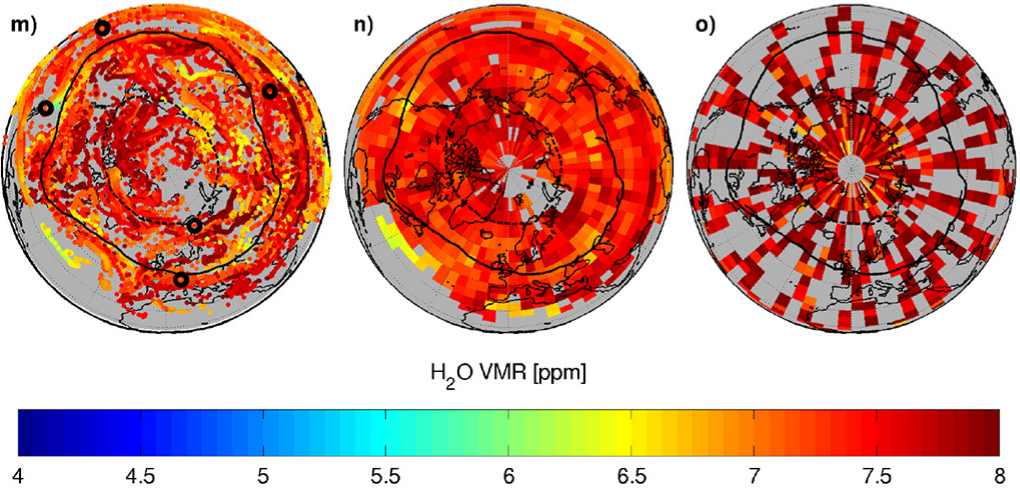
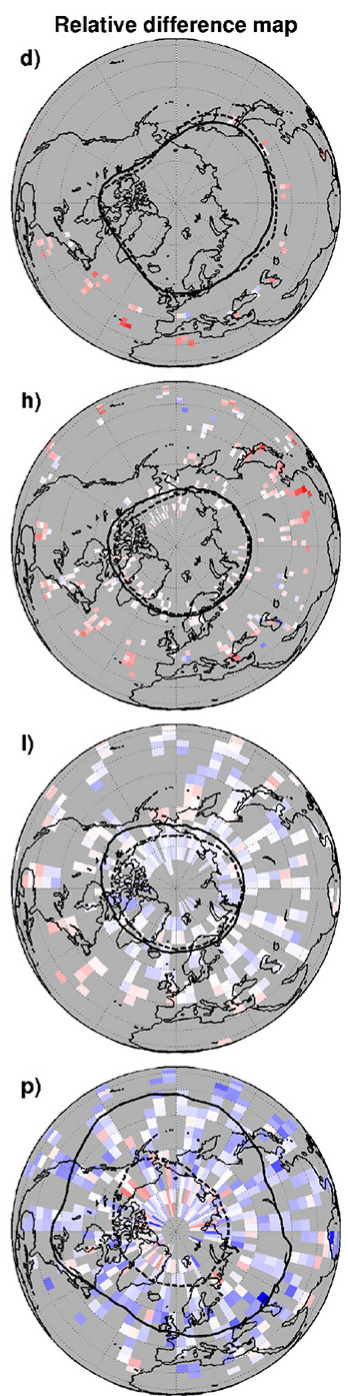

Rel. diff. (TM,MLS) [\%]

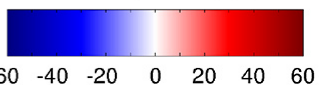

Figure 4. Case B: same as Fig. 3, except for 22 September 2012, 12:00 UTC close to the fall equinox.

China just south of the stratospheric vortex as Fig. 3b reveals. The coverage over Europe is in contrast quite good. With increasing altitude, the water vapor observations from Sodankylä almost reach the inner mesospheric vortex edge in case A (28 February 2012), but data from MIAWARA-C still mainly contribute for the part of the map which is framed by the vortex. Contrarily in the two higher altitude regions (Fig. $3 \mathrm{j}$ and $\mathrm{n}$ ) the hemispherical coverage of water vapor data is much better in the synthesized domain-averaged TM map than in the Aura MLS map (Fig. 3k and o). A main advantage of the synthesized water vapor maps is a temporal coherent data set without any post-processing, covering over $95 \%$ of the Northern Hemisphere on the 1 and $0.1 \mathrm{hPa}$ pressure level. The area covered by TM data is remarkable and similar to that in the TM case scenario B for the $0.1 \mathrm{hPa}$ and $\mathrm{D}$ for the 1 and $0.1 \mathrm{hPa}$ pressure level (see Figs. $4 \mathrm{n}$ and $7 \mathrm{j}$ and $\mathrm{n}$ ). The minimum $\mathrm{H}_{2} \mathrm{O}$ mixing ratios inside the $1 \mathrm{hPa}$ (stratopause) and $0.1 \mathrm{hPa}$ vortices coincide very well. An eastward shift in the position of the lowest VMR domains is apparent between the Aura MLS and TM water vapor maps for the stratopause region. A mesospheric vortex position at $0.1 \mathrm{hPa}$ can be seen in both TM and direct satellite observation techniques (Fig. 3n and o). A perceptible difference between Fig. $3 \mathrm{~m}$ and $\mathrm{n}$ in areas with low water vapor is likely due to the applied correction for vertical averaging in the domain TM map (cf. Sect. 2.4).

TM case B is represented in Fig. 4. The trajectory mapping target time was 22 September 2012, 12:00 UTC, the second 

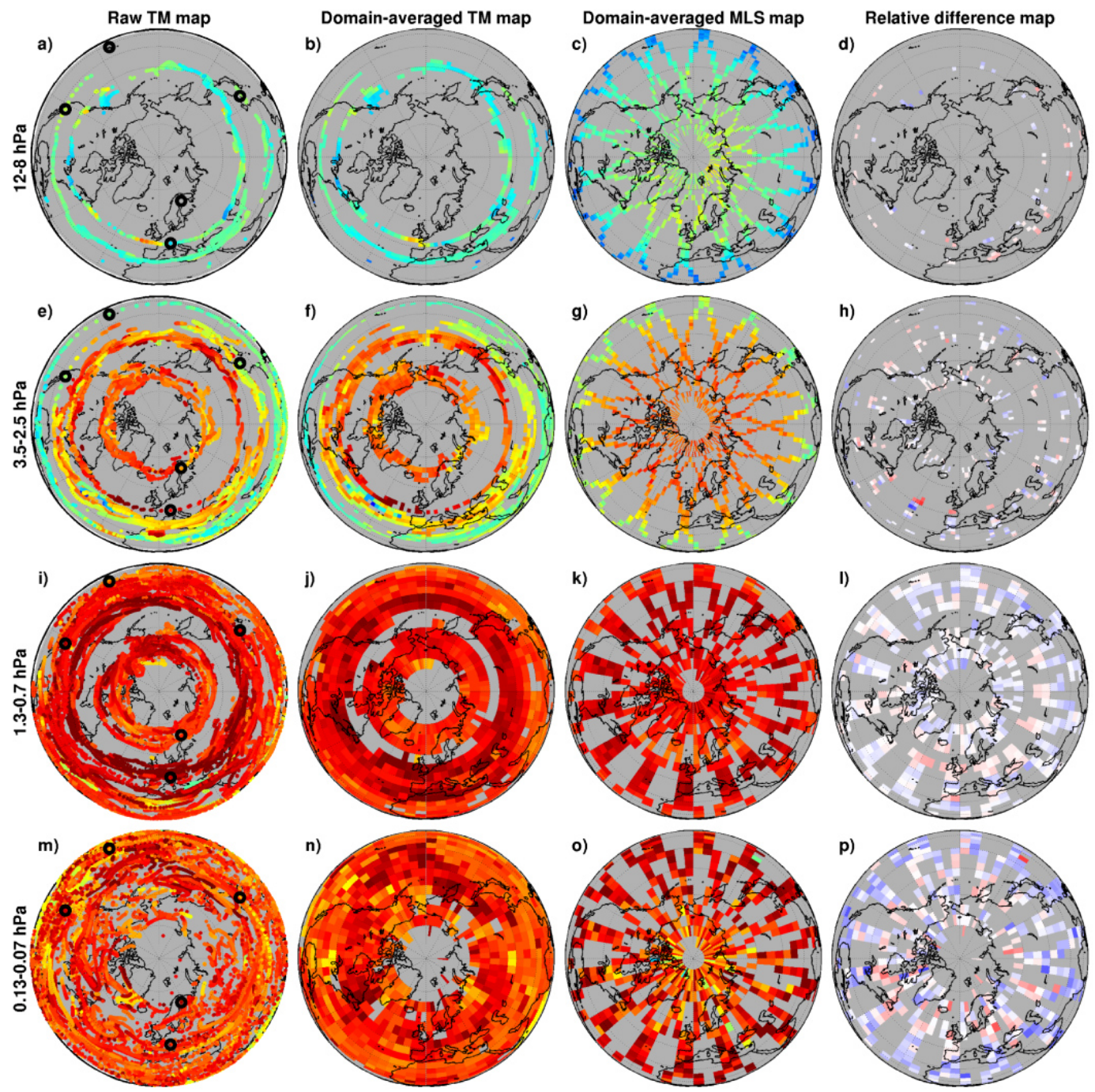

$\mathrm{H}_{2} \mathrm{O}$ VMR $[p p m]$

Rel. diff. (TM,MLS) [\%]

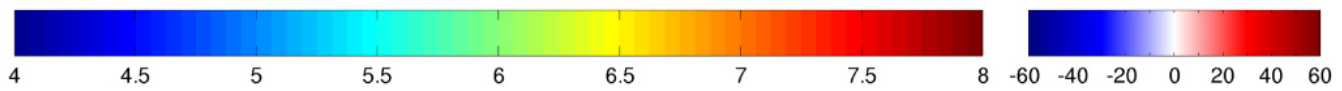

Figure 5. Case C: same as Fig. 3, except for 21 June 2012, 12:00 UTC close to the June solstice.

day of equinox in the year 2012. A rapid increase in planetary wave mode 1 usually occurs near the fall equinox in the Northern Hemisphere, and their propagated and transferred momentum drives the zonal west wind circulation in the middle atmosphere (Liu et al., 2001). Regarding the considered pressure layers, inside-the-vortex measurements from the ground-based instrument network were always available on the TM target date, if the measurement response down to $10 \mathrm{hPa}$ was high enough. Nevertheless there is the possibility that subsiding air from higher altitudes can provide TM data down to lower altitudes. The polar vortex edge detection algorithm worked for the equinox scenario (B) and the reformed vortex after the summer season. For the mesospheric vortex (see Fig. 4m), a large vertical gradient of the edge is evident, where a 3-dimensional interpretation would be cone-shaped.

The hemispheric coverage of the TM $\mathrm{H}_{2} \mathrm{O}$ VMR data of case study B in the stratosphere and on stratopause level (Fig. 4a, e and i) is not as good as for the previous case study A, but similar for the $0.1 \mathrm{hPa}$ pressure level. Some larger measurement gaps between 12 September and 2 October 2012 in the Table Mountain and Hawaii data lead to a reduced number of the TM values of water vapor in case B. The visual impression of the comparison between Fig. $4 \mathrm{f}$ and $\mathrm{g}$ gives the result that TM can reproduce the $\mathrm{H}_{2} \mathrm{O}$ VMR within a few percent of relative difference along the inner black vortex contours, as the relative difference maps to Aura MLS observations (Fig. 4h) prove. Horizontal meridional $\mathrm{H}_{2} \mathrm{O}$ VMR 


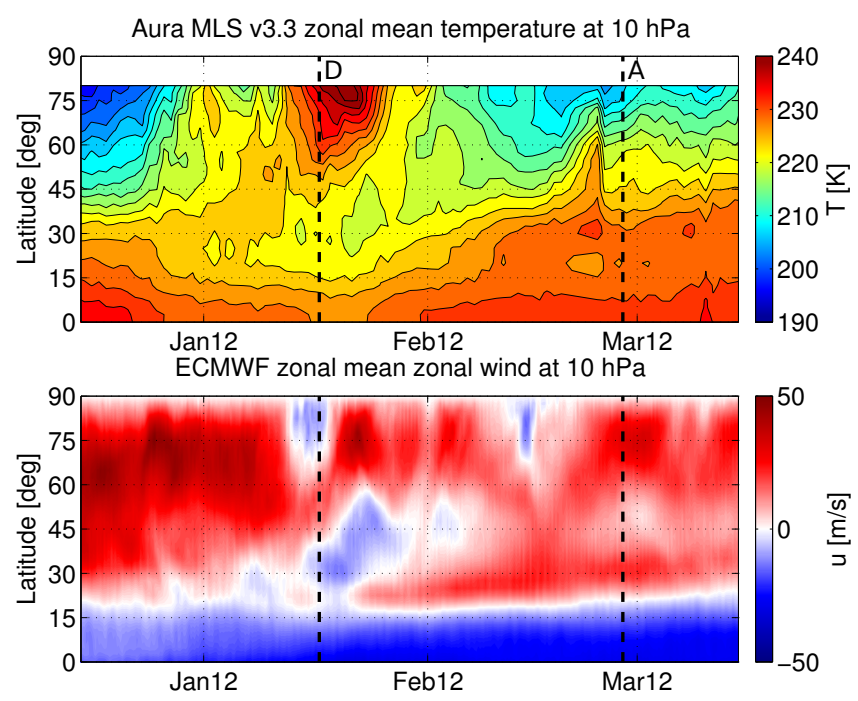

Figure 6. Northern hemispheric Aura MLS v3.3 zonal mean temperature in $[\mathrm{K}]$ (upper panel) and ECMWF zonal mean zonal wind in $\left[\mathrm{m} \mathrm{s}^{-1}\right]$ for the $10 \mathrm{hPa}$ pressure level. The time period extends from mid-December 2011 to mid-March 2012. The left dashed black line indicates the date of TM case D and the right one TM case A.

gradients match well between Aura MLS and TM maps for the 3 and $1 \mathrm{hPa}$ altitude. At $0.1 \mathrm{hPa}$ trajectory-mapped water vapor tends to be too low on the order of $5-10 \%$, as is obvious in Fig. 4p, where bluish domains are prevalent. In general, horizontal gradients in water vapor were found to be higher in the stratosphere than in the mesosphere near equinox.

To sum up so far, Aura MLS water vapor observations show a quite good and widespread agreement over the analyzed pressure levels of case scenarios A and B in relation to the generated TM maps, which have more noise (variability between neighboring domains) in water vapor. Reducing the noise of TM data without smoothing algorithms is difficult. More accurate wind field data with a higher temporal resolution could improve the TM quality in the sense of decreasing noise in the horizontal water vapor distribution and trajectory position errors.

\subsection{TM in a non-polar vortex regime - case study $C$}

The prevailing wind direction in the middle atmosphere reverses seasonally, in winter the winds are mainly eastward and in summer westward. Enhanced gravity wave activity during $\mathrm{NH}$ winter leads to a deposition of angular momentum in the middle atmosphere and decelerates the zonal flow. Meridional transport of atmospheric constituents in summer is limited, because of missing wave-induced forces driving north-south circulations (Holton and Alexander, 2000). As a consequence, trace constituents in the NH summer stratoand mesosphere become fairly evenly distributed around lat- itudinal bands within weeks because there are no dynamical barriers to atmospheric transport as provided by the wintertime stratospheric polar vortex. Circle like structures in the TM water vapor maps of Fig. 5, close to the June solstice, exemplify the situation. With only five measurement locations, whereof two (Seoul and Table Mountain) are almost at the same latitude, the hemispheric coverage compared to Aura MLS is poor. If we intend to reduce the water vapor gaps in summer time, ground-based observations of more latitudes from tropical to polar regions would be necessary. Stations located at various longitudes are much more important in the winter than in the summer period. A spatial interpolation of $\mathrm{H}_{2} \mathrm{O}$ in environments where the horizontal gradient is small (Fig. $5 \mathrm{c}$ and g) or even absent (Fig. 5k) could be taken into consideration to fill in the gaps. For filling in data gaps in the satellite observational record, analysis or reanalysis data from e.g., ECMWF could be used. Thus an increased number of possible comparison domains would be created. This concept has not been implemented, because the accuracy of moisture fields in ECMWF model could be problematic in the upper atmosphere. Some studies (e.g., Feist et al., 2007) found that the ECMWF model produces an unrealistically moist mesosphere, which is not present in the MLS observations. And more importantly, there is no stratospheric $\mathrm{H}_{2} \mathrm{O}$ data assimilated in the ECMWF integrated forecasting system (IFS), and we think that using the model data above the troposphere is not an alternative regarding the TM map validation.

In the stratosphere of case study $\mathrm{C}$ the difference between the highest (high LAT) and lowest (low LAT) mixing ratios is on the order of $1 \mathrm{ppm}$, what is confirmed by TM (see Fig. 5b and f). The $10 \mathrm{hPa}$ trajectory map shows that WVMS6 and MIAWARA-C instruments are not able to provide valuable scientific information for this pressure layer $(12-8 \mathrm{hPa})$.

The $\mathrm{H}_{2} \mathrm{O}$ VMR distribution at the 1 and $0.1 \mathrm{hPa}$ level is quite uniform and reaches values between 7 and $8 \mathrm{ppm}$ as 3 months later in the case of scenario B. With increasing altitude, the water vapor coverage over the Northern Hemisphere is found to increase in the TM plots (Fig. 5a, e, i and m). The short-scale $\mathrm{H}_{2} \mathrm{O}$ variation (noise) is obvious in the Aura MLS map in Fig. 50.

\subsection{Performance during the January 2012 SSW - case study D}

We restrict the temporal description of the major SSW of January 2012 to Aura MLS zonal mean temperature measurements and ECMWF zonal mean zonal winds on the $10 \mathrm{hPa}$ pressure surface. Figure 6 shows a strong negative temperature gradient north of $40^{\circ} \mathrm{N}$ right before the end of December 2011 in connection with the stratospheric polar vortex. At the beginning of January 2012, the temperature gradient started to weaken and reversed near the middle of the month. The increase in zonal mean temperature in the polar stratosphere is about $25 \mathrm{~K}$ during 1 week. In the same period of 

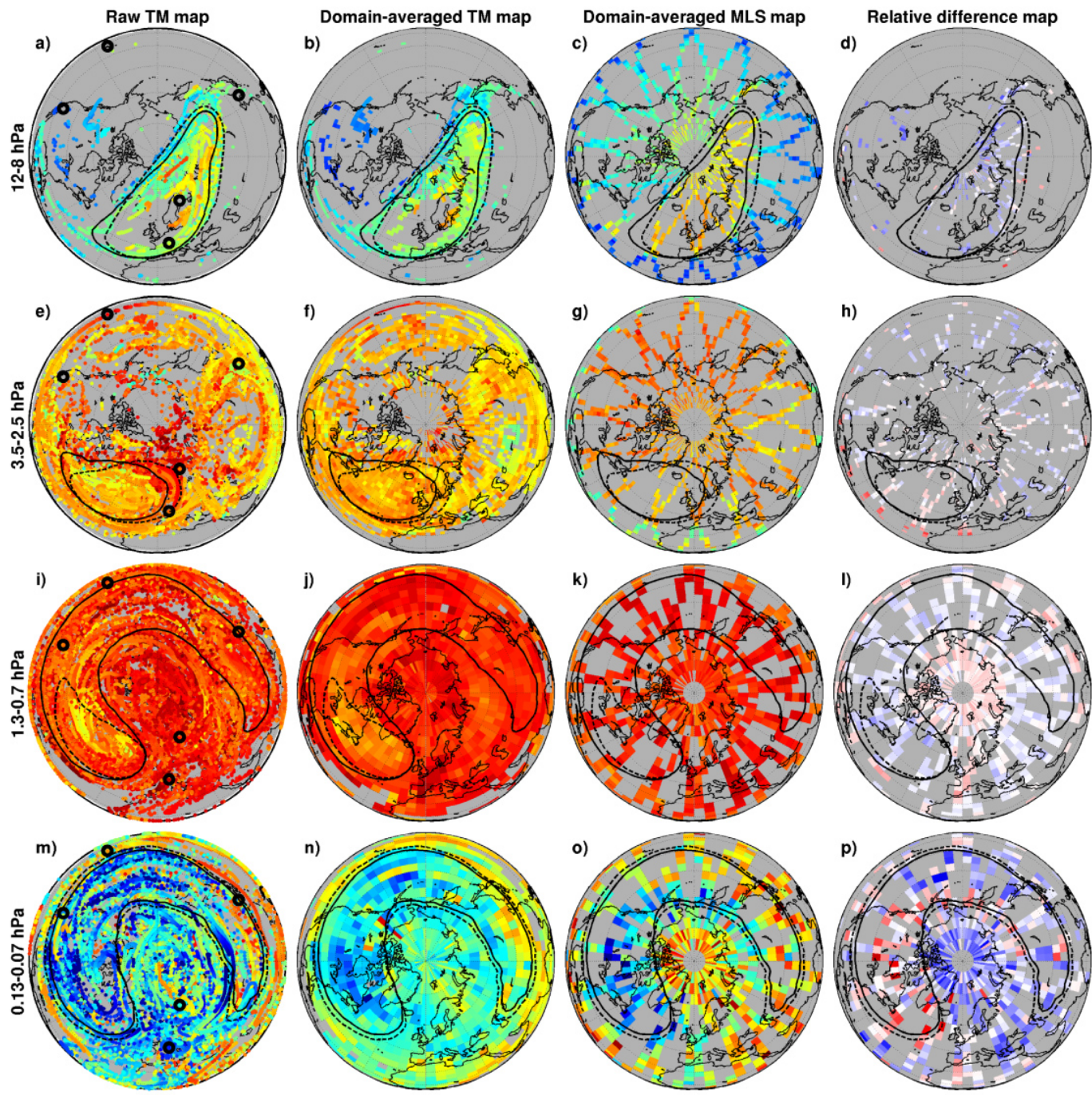

$\mathrm{H}_{2} \mathrm{O}$ VMR [ppm]

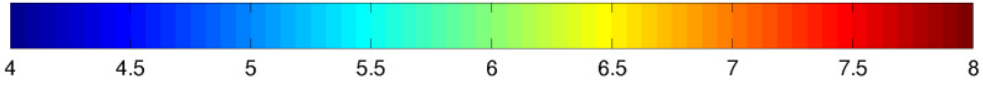

Rel. diff. (TM,MLS) [\%]

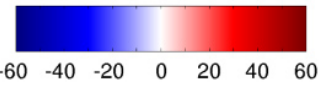

Figure 7. Case D: same as Fig. 3, except for 17 January 2012, 12:00 UTC close to the maximum temperature increase at $10 \mathrm{hPa}$ during a major SSW in the Northern Hemisphere.

time, the ECMWF operational analysis of the mean zonal wind component shows a reversal from westerly to easterly winds. Compared to the January 2010 major SSW, described in Scheiben et al. (2012), the temperature increase in this case was not so abrupt and also the duration of the easterlies at $10 \mathrm{hPa}$ did not persist as long. After the SSW the temperatures decreased again in the stratosphere north of $45^{\circ} \mathrm{N}$, but did not reach as low values as in December $2011(\sim 205 \mathrm{~K}$ compared to $190 \mathrm{~K}$ ) owing to a less intense reformation of the polar vortex.

Case D (Fig. 7) occurs near the time of the maximum temperature observed on $10 \mathrm{hPa}$ during the $2012 \mathrm{SSW}$. The distortion and weakening of the vortex is a difficult situation for applying trajectory mapping. By comparing the position of the vortex edge contours between 10 and $3 \mathrm{hPa}$, big differences in size and position can be found. The mean vortex edge horizontal wind velocities decline by almost $10 \mathrm{~m} \mathrm{~s}^{-1}$ when going up in altitude from 10 to $3 \mathrm{hPa}$. Usually, in an undisturbed and stable circulation environment in $\mathrm{NH}$ winters the opposite (increasing wind speeds with altitude) is typical in the stratosphere. Regarding the trajectory map and MLS $\mathrm{H}_{2} \mathrm{O}$ footprints on the $10 \mathrm{hPa}$ reference layer a good match is found (cf. Fig. $7 b-d$ as well as $\mathrm{f}-\mathrm{h}$ ).

Trajectory mapping of water vapor in the mesosphere during a SSW provides synoptic maps of slightly reduced quality and higher errors (Fig. 7n and p). However in this instance 
it is found to work even better than in case A with a stable polar vortex environment. To perfectly match the noisy Aura MLS map (Fig. 7o) is by chance very unlikely. The correlation between these differences (TM - MLS) and photolytic or chemical processes, which are entirely neglected, is not evaluated. We note that the ECMWF winds become increasingly uncertain with increasing altitude, and may contribute significantly to the observed differences between MLS and the ground-based radiometers.

\subsection{Modification of ECMWF mesospheric wind velocities - case study $D^{\star}$}

Additionally we want to briefly describe a performed sensitivity study with the ECMWF wind field data, that might improve mesospheric trajectory positions. Based on measurements from the ground-based microwave Doppler wind radiometer WIRA (Rüfenacht et al., 2014) during different campaigns, which suggests that ECMWF wind components $(u, v$ and $w$ ) are overestimated in the mesosphere (above $1 \mathrm{hPa}$ ) by the model, a constant downscaling of $u, v$ and $w$ by $30 \%$ on all model grid points above $1 \mathrm{hPa}$ has been performed and new trajectories were calculated with LAGRANTO for the SSW case study D to synthesize new $\mathrm{H}_{2} \mathrm{O}$ trajectory maps (case study $\mathrm{D}^{\star}$ ). Compared to the Aura MLS water vapor maps a non-significant improvement in the 0.13-0.07 hPa pressure layer could be detected (cf. last two columns in Table 2). Less than $4 \%$ more coincident relative comparison domains display a difference of up to $\pm 10 \%$ to Aura MLS $\mathrm{H}_{2} \mathrm{O}$ VMR domains. From this point of view it is not possible to cross-check and prove whether the ECMWF winds in the mesosphere are indeed too high. An assessment for effects of potential error sources in the TM analysis, such as wind errors, chemical reactions or a removal of water vapor by phase transitions (e.g., mesospheric clouds), is presented in Sect. 3.6.

\subsection{Validation and statistical analysis with MLS}

In addition to the relative difference maps shown before, histograms are plotted for every individual case study to illustrate the number of matching domains corresponding to deviation bins with a width of $5 \%$ in the pressure layers. The histograms and relative difference maps are used for a statistical analysis and validation. Table 2 further summarizes the percentage of $\mathrm{H}_{2} \mathrm{O}$ VMR domains within 10, respectively $20 \%$ relative difference ( $D_{\text {rel }}$, see Eq. 3 ) between TM and Aura MLS results. Further, percentages corresponding to the TM performance without instrument bias corrections are given.

The relative differences to Aura MLS in the domain areas do not exceed $20 \%$ in most cases and altitude regions. Regarding the whole number of domains per map, only a few outliers with deviations $D_{\text {rel }}>| \pm 20| \%$ are present at pressure levels below $0.1 \mathrm{hPa}$ as confirmed in the histogram charts (Fig. 8). The deviation bins with the maximum number of relative difference domains (peak of Gaussian curve) are centered around the zero percent line (perfect coincidence), except for the lowest altitude in case study B and D where the TM domains show either too high (case B) or too low (case D) $\mathrm{H}_{2} \mathrm{O}$ VMR values and for the highest altitude in all cases where overly low mixing ratios from TM dominate.

Table 2 underlines the good results of the TM approach with respect to Aura MLS observations. Referred to the bias corrected row values of case $\mathrm{A}$ and $\mathrm{B}$ in the stratosphere and stratopause level $(1 \mathrm{hPa})$, between 98.4 and $100 \%$ of the compared domains have a difference of less than $\pm 20 \%$. At least around half of all domains from the investigated difference maps in Figs. 3 and $4 d$ and $h$ are indeed within $\pm 10 \%$. By ignoring case $\mathrm{B}$ with its small statistical significance, slightly over $82 \%(83 \%)$ of the domains agree within $\pm 10 \%$ in case A at $10 \mathrm{hPa}(3 \mathrm{hPa})$. Within the mesospheric vortices a significant number of domains show that $\mathrm{TM}$ resulted in too high $\mathrm{H}_{2} \mathrm{O}$ VMR values (reddish colors in the February polar vortex case study in Fig. 3p). Inside the equinox polar vortex this feature is not present. In the histogram of case A $(0.1 \mathrm{hPa})$ roughly 15 domains exist with a difference of $95-100 \%$, located in the vortex over Greenland and westwards thereof. While the Gaussian center line still lies close to the zero percent line (green), the shape of the histogram spreads. The homogeneous distributed water vapor in case study B at $0.1 \mathrm{hPa}$ with values around 7 to $8 \mathrm{ppm}$ (Fig. 4o) is better confirmed by TM than in the previous situation. In numbers we now count $46.1 \%$ (case study A) and $80 \%$ (case study B) of the domains to be within the $\pm 10 \%$ deviation limit but at least 75.7 and $99.4 \%$ are within the doubled deviation threshold of $20 \%$.

Regarding TM case study C (21 June 2012) close to the June solstice event, the number of coincident TM and MLS domains is reduced on the investigated stratospheric pressure levels owing to zonal circulation patterns compared to case study A or D. Throughout the middle atmosphere, all relative difference domains from high to low latitude bands show only light blue to light red colors (Fig. 5d, h, 1 and p). The deviations in $\mathrm{H}_{2} \mathrm{O}$ VMR are tiny, the histograms are always narrow. More than $350(200) 5^{\circ} \times 5^{\circ}$ domains are within \pm 5 $\%$ at $1 \mathrm{hPa}(3 \mathrm{hPa})$ and nearly all compared areas show less than $20 \%$ relative difference (cf. Table 2 ) on all four altitude levels.

Next we show the agreement of TM results with MLS observations in case study D (17 January 2012), the SSW event. As it is affirmed by Fig. 7, the prolonged shape of the vortex is very well represented by the applied trajectory mapping method at the lowest investigated altitude. Less than $2 \%$ of the compared domains deviate more than $20 \%$ in relative difference. Examining the variations in $\mathrm{H}_{2} \mathrm{O}$ VMR of the inner parts of the $3 \mathrm{hPa}$ vortex on 17 January 2012, the outcome has to be evaluated positively with a majority of domains that satisfy the $10 \%$ relative difference quality criterion (Figs. $7 \mathrm{~h}$ and 8 ). The more or less uniform $\mathrm{H}_{2} \mathrm{O}$ distribution of 7$7.5 \mathrm{ppm}$ in MLS (Fig. 7k) could be displayed correctly by 

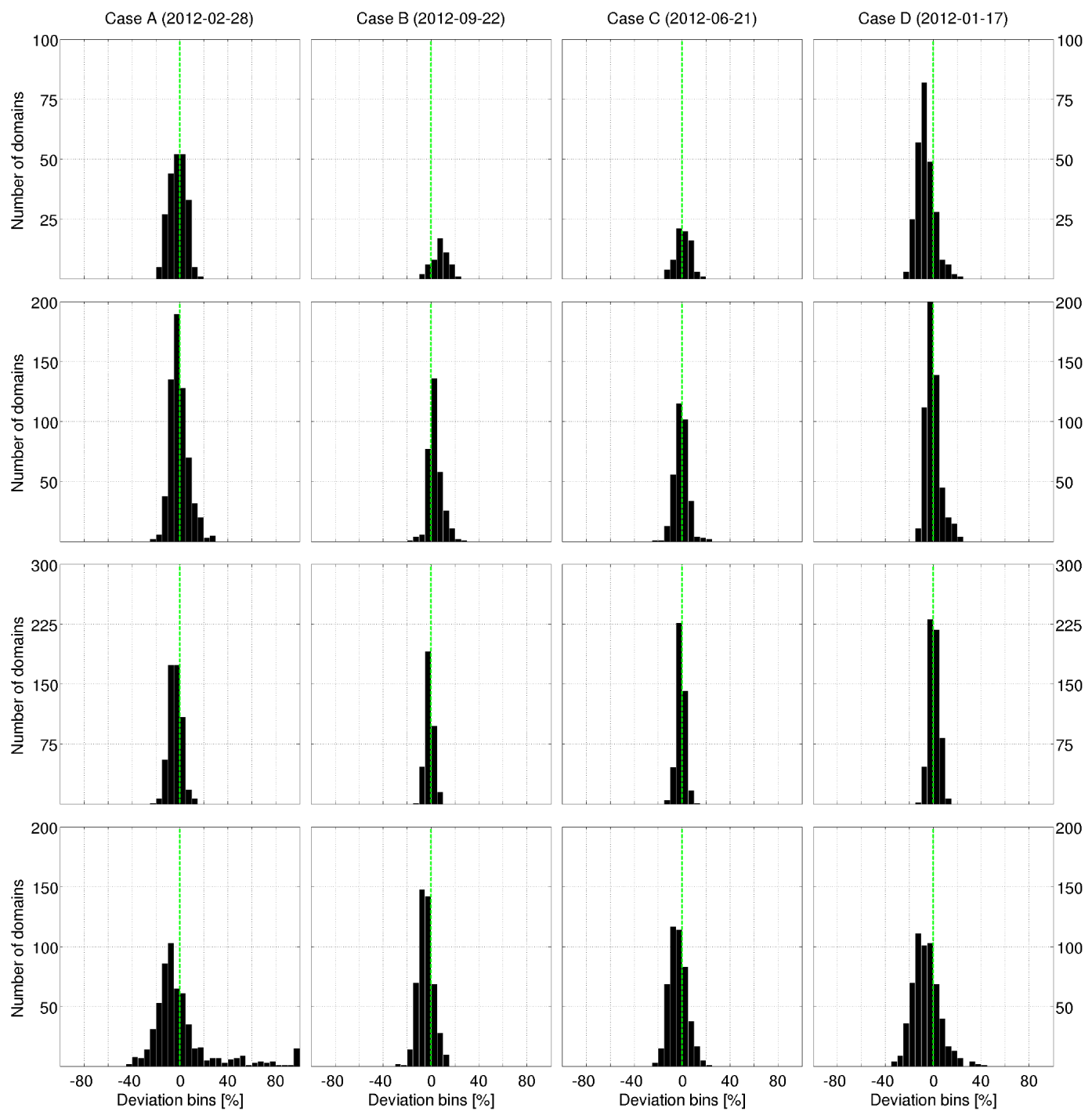

Figure 8. Pressure layer corresponding histograms of TM case study A (28 February 2012, first column), B (22 September 2012, second column), C (21 June 2012, third column) and D (17 January 2012, fourth column). The number of relative difference (TM - MLS) domains in a certain deviation bin of a width of $5 \%$ between TM and Aura MLS solution is shown. From top to bottom, the pressure layers are 12-8, 3.5-2.5, 1.3-0.7 and 0.13-0.07 hPa. Vertical green lines indicate zero deviation.

TM (Fig. 7j). There, the relative differences to MLS never exceed $20 \%$. At $0.1 \mathrm{hPa}$ the water vapor VMR underestimation by TM is reduced compared to case $\mathrm{A}$ at the same altitude. More than $53 \%$ (89\%) of the compared domains stay within a relative difference of $10 \%(20 \%)$. In the mean, TM domains revealed low mixing ratios relative to MLS in the mesospheric pressure layer as the leftward shifted peak of the histogram reveals.

Summarizing cases A to D, very good agreement between TM- and MLS-derived water vapor maps was found at the stratopause level $(1 \mathrm{hPa} \sim 48 \mathrm{~km})$. All TM domains for case B, C and D deviate less than $20 \%$ from MLS (see Table 2) and only a tiny percentage of $0.2 \%$ show larger relative differences in case A. Of course histograms show tight bounds and the full widths at half maxima are small (Fig. 8). We assume that low planetary wave activity in the upper stratosphere around the selected TM dates was accountable for the low meridional gradients in water vapor in this altitude region and hence simplified the TM method to work well.

\subsection{Error estimation of TM approach}

In this section, the strategy and outcome of the investigation to estimate the error and limitation of the trajectory mapping (TM) approach is briefly summarized. In a first step Aura MLS profiles are taken, located near the five groundbased observation sites. The chosen criterion for spatial coincident of the satellite measurements is $600 \times 300 \mathrm{~km}$ around 
Table 2. The percentage of coincident domains in which the $\mathrm{H}_{2} \mathrm{O}$ from TM and Aura MLS observations agree within 10 (20) $\%$ in each pressure layer. All four studied TM scenarios (A-D) with applied bias correction (Y), according to Sect. 2.2, or no correction (N) are shown. In the last column the percentages regarding the ECMWF sensitivity case study $\mathrm{D}^{\star}$ (30\% downscaled mesospheric wind velocities for TM) are given.

\begin{tabular}{lccccc}
\hline $\begin{array}{l}\text { TM Case } \\
\text { Date }\end{array}$ & $\begin{array}{c}\mathrm{A} \\
\text { 28 Feb 2012 }\end{array}$ & $\begin{array}{c}\mathrm{B} \\
\text { 22 Sep 2012 }\end{array}$ & $\begin{array}{c}\mathrm{C} \\
\text { 21 Jun 2012 }\end{array}$ & $\begin{array}{c}\mathrm{D} \\
\text { 17 Jan 2012 }\end{array}$ & $\begin{array}{c}\mathrm{D}^{\star} \\
\text { 17 Jan 2012 }\end{array}$ \\
\hline $\begin{array}{l}12-8 \mathrm{hPa}(\mathrm{N}) \\
12-8 \mathrm{hPa}(\mathrm{Y})\end{array}$ & $77.6(99.1)$ & $56.9(96.1)$ & $84.9(100)$ & $70.9(93.9)$ & $70.9(93.9)$ \\
\hline $3.5-2.5 \mathrm{hPa}(\mathrm{N})$ & $72.5(96.8)$ & $87.0(99.7)$ & $59.2(93.7)$ & $56.4(96.1)$ & $57.9(95.6)$ \\
$3.5-2.5 \mathrm{hPa}(\mathrm{Y})$ & $83.1(98.4)$ & $86.0(99.1)$ & $92.7(99.1)$ & $91.1(99.3)$ & $91.7(99.3)$ \\
\hline $1.3-0.7 \mathrm{hPa}(\mathrm{N})$ & $37.7(94.0)$ & $57.7(99.7)$ & $51.4(99.3)$ & $66.0(99.8)$ & $74.4(99.6)$ \\
$1.3-0.7 \mathrm{hPa}(\mathrm{Y})$ & $87.0(99.8)$ & $99.7(100)$ & $98.6(100)$ & $98.5(100)$ & $98.4(100)$ \\
\hline $0.13-0.07 \mathrm{hPa}(\mathrm{N})$ & $26.0(66.5)$ & $16.3(84.7)$ & $35.1(88.7)$ & $35.1(75.1)$ & $40.0(80.6)$ \\
$0.13-0.07 \mathrm{hPa}(\mathrm{Y})$ & $46.1(75.7)$ & $80.0(99.4)$ & $76.2(99.1)$ & $53.3(89.3)$ & $57.2(89.8)$ \\
\hline
\end{tabular}

the ground-based radiometer locations. The $300 \mathrm{~km}$ go along north-south direction, while the $600 \mathrm{~km}$ go along east-west direction. The unequal lengths are due to typical water vapor gradients, which tend to be much smaller in zonal than meridional direction. A similar way of data processing has been applied to the obtained Aura MLS profile time series, according to Sect. 2.4. It is evident that correction factors to account for biases are not necessary, since the same instrument is used to generate the $\mathrm{H}_{2} \mathrm{O}$ profiles. The histogram charts in Fig. 9 show the results of the investigation. These charts are similar to the ones in Fig. 8 only with additional tags for the standard deviations $\pm \sigma$.

For the three pressure layers at lower altitudes (12-8, 3.52.5 and $1.3-0.7 \mathrm{hPa}$ ) it is found that deviations from the coincident domain comparison never exceed $20 \%$. Approximately $2 / 3$ of all domains show less than $10 \%$ deviation. The errors become significantly higher in the mesosphere $(0.13-0.07 \mathrm{hPa})$. Estimating the position of the $2 / 3$ value of the domains in the bar charts, it is now roughly within $\sim 20 \%$ (doubled) in the mesospheric pressure layers. Regarding the standard deviation $\sigma$, it is clear that the uncertainties of TM are largest in the mesosphere $(0.13-0.07 \mathrm{hPa})$ of case study A (28 February 2012). It is also noticeable that TM during the SSW case D (17 January 2012) reveals less uncertainties ( $\sigma$ is smaller).

\section{Summary and discussion}

We have generated $\mathrm{NH}$ middle atmospheric water vapor maps from five single water vapor profile measurement sites, mainly operated in the frame of NDACC, by use of a spatial domain-averaging trajectory mapping technique. Forward and backward trajectories were calculated for up to 10 days with LAGRANTO driven by ECMWF operational analysis wind field data. A total of four TM case-by-case studies were presented and discussed, belonging to differ- ent atmospheric circulation patterns and seasons of the year. Apart from the SSW scenario (D) in January 2012, we discussed (1) a stable polar vortex case (A) at the end of February, (2) a case near June solstice (C) and (3) a fall equinox scenario (B). For each case study four pressure layers from the stratosphere (centered at $10 \mathrm{hPa}$ ) to the lower mesosphere (centered at $0.1 \mathrm{hPa}$ ) were analyzed.

Biases between the ground-based instruments have been corrected using coincident Aura MLS observations during a defined time period (August 2010 to September 2014). Calculated mean relative difference profiles of $\mathrm{H}_{2} \mathrm{O}$ served as correction factors to harmonize the data sets. The improvements of the bias corrected synoptic maps is very pronounced above the $3 \mathrm{hPa}$ pressure layer compared to the uncorrected versions (Table 2). At best (case study B, $0.1 \mathrm{hPa}$ ), $80 \%$ instead of $16.3 \%$ of the relative difference domains had a bias of only $\pm 10 \%$. For the three upper pressure layers of TM studies $\mathrm{A}, \mathrm{C}$ and $\mathrm{D} / \mathrm{D}^{\star}$, the corrections led always to an improvement of trajectory-mapped data, referring to the $\pm 10 \%$ as well as to the $\pm 20 \%$ regime. On the 10 and $3 \mathrm{hPa}$ pressure level the applied correction factors led sometimes to a slight worsening for cases $\mathrm{B}$ and $\mathrm{D} / \mathrm{D}^{\star}$, for instance a loss of almost $10 \%$ of comparison domains (case D/D $\mathrm{D}^{\star}$ on $10 \mathrm{hPa}$ ), which were associated to the $10 \%$ quality threshold.

The mesospheric polar vortex edge was very well reproduced, with the trajectory mapping method by the northsouth gradient in water vapor VMR on 28 February 2012 (Fig. 3n). In the mesosphere, where uncertainties in the 3dimensional wind field become larger, leading to trajectory position errors, the quality of the TM-derived water vapor distribution is generally reduced, compared to coincident Aura MLS observations. However, the TM data coverage is found to be better at higher altitudes such as at the $0.1 \mathrm{hPa}$ level in the mesosphere. In addition, the assumption of unchanged mixing ratios along $240 \mathrm{~h}$ trajectories might not be sufficient any more in mesospheric altitudes where photolysis or chemical reactions of water vapor cannot be totally 

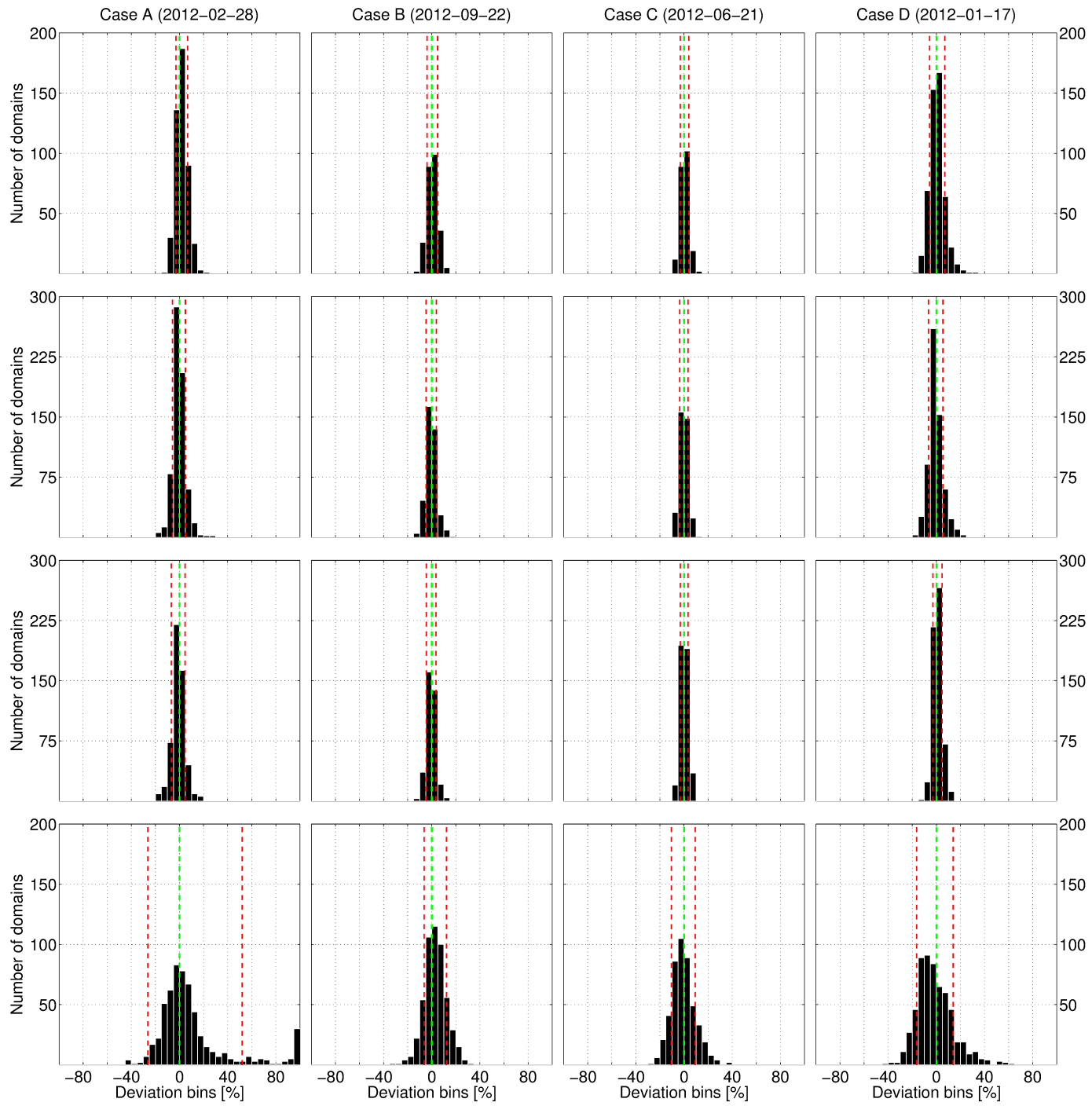

Figure 9. Histogram charts for estimating the error of TM approach in case study A (28 February 2012, first column), B (22 September 2012, second column), C (21 June 2012, third column) and D (17 January 2012, fourth column) with advection of $\mathrm{H}_{2} \mathrm{O}$ profiles from Aura MLS instead of ground-based measured profiles. The number of relative difference (TMMLS - MLS) domains in a certain deviation bin of a width of $5 \%$ between TM MLS and Aura MLS solution is shown. From top to bottom the pressure layers are 12-8, 3.5-2.5, 1.3-0.7 and $0.13-0.07 \mathrm{hPa}$. Vertical green lines indicate zero deviation and red dashed lines mark the standard deviations $( \pm \sigma)$.

ignored. But the analysis of the statistical outcome in the validation part (Sect. 3.5) shows that the VMR values of the vast majority of spatial domains match between the TM and Aura MLS result. After having assessed the errors of the TM method (cf. Fig. 9), it is found that there is not much of a difference observed between Fig. 9 and the real TM case studies. This is a sign that a kind of optimal result has been obtained in consideration of the errors in wind, chemistry or removal from condensed phases, which cannot be avoided within the TM method.

Predominantly good TM results could be obtained for stratospheric pressure layers, including the stratopause region at $1 \mathrm{hPa}$. Keeping in mind that complex polar vortex deformations occurred during the SSW time period of case scenario D (Sect. 3.3). Based on calm circulation patterns, prevailing zonal winds and small meridional water vapor VMR gradients, the summer case study C on 21 June 2012 (Sect. 3.2) showed, beside case B on 22 September 2012, the best quantitative result, affirmed by Table 2 and Fig. 8 statistics.

\section{Conclusions}

We conclude that the applied trajectory mapping technique (Sect. 2.4) is able to produce synoptic water vapor maps of high quality throughout stratospheric and mesospheric alti- 
tude levels. However errors related to the TM approach are roughly doubled inside mesospheric pressure layer $(0.13-$ $0.07 \mathrm{hPa}$ ), which limits the benefit of the technique at these high altitudes (see Sect. 3.6).

The occurring of big data gaps in the pressure layer between 12 and $8 \mathrm{hPa}$ based on measurement cut-off criteria could be problematic. Instruments that can provide measurements with tolerable a priori influences down to an altitude of $10 \mathrm{hPa}$ or even below are required to improve these maps.

In order to ensure a good representation of water vapor inside and along the edge of $\mathrm{NH}$ polar vortex more than one high latitude $\left(>60^{\circ} \mathrm{N}\right)$ measurement site in the rear of the polar front is highly desirable. Within our investigation only one out of five ground-based radiometers was located north of $60^{\circ} \mathrm{N}$ (MIAWARA-C), but the instrument retrievals in the lower stratosphere were affected by high a priori contributions (measurement response $<60 \%$ ), leading to $\mathrm{H}_{2} \mathrm{O}$ profile data omissions. Thus TM data inside the stratospheric vortex in case study A, B and D is missing or reduced. The employed techniques could be applied to ozone and other long-living trace gases in the middle atmosphere. Trajectory mapping cannot completely replace satellite measurements, but it has to be seen as an independent data source in addition to satellite measurements and model simulations with the possibility to increase our understanding of middle atmospheric trace gases.

Acknowledgements. This work has been supported by the Swiss National Science Foundation under grant number 200020-146388 and by MeteoSwiss in the frame of the GAW project "Fundamental GAW parameters measured by microwave radiometry". J. J. Oh acknowledges the support by the National Research Foundation of Korea (NRF) grant funded by the Korean Government (MSIP) (No. 2013070600). Further on we thank ECMWF for the access to the operational analysis data. We appreciate NASA for access to EOS Aura MLS data and NDACC for making water vapor profiles from ground-based microwave radiometers available for the public. Finally, we thank the two reviewers for helpful comments to improve the paper.

Edited by: G. Stiller

\section{References}

Allen, M., Yung, Y. L., and Waters, J. W.: Vertical transport and photochemistry in the terrestrial mesosphere and lower thermosphere (50-120 km), J. Geophys. Res.-Space, 86, 3617-3627, doi:10.1029/JA086iA05p03617, 1981.

Bacmeister, J. T., Kuell, V., Offermann, D., Riese, M., and Elkins, J. W.: Intercomparison of satellite and aircraft observations of ozone, CFC-11 and $\mathrm{NO}_{\mathrm{y}}$ using trajectory mapping, J. Geophys. Res., 104, 16379-16390, doi:10.1029/1999JD900173, 1999.

Bevilacqua, R., Olivero, J., Schwartz, P., Gibbins, C., Bologna, J., and Thacker, D.: An observational study of water vapor in the mid-latitude mesosphere using ground-based mi- crowave techniques, J. Geophys. Res.-Oceans, 88, 8523-8534, doi:10.1029/JC088iC13p08523, 1983.

Brasseur, G. and Solomon, S.: Aeronomy of the Middle Atmosphere: Chemistry and Physics of the Stratosphere and Mesosphere, vol. 32, Springer, 2006.

Deuber, B. and Kämpfer, N.: A new 22-GHz radiometer for middle atmospheric water vapor profile measurements, IEEE T. Geosci. Remote, 42, 974-984, doi:10.1109/TGRS.2004.825581, 2004.

Deuber, B., Haefele, A., Feist, D. G., Martin, L., Kämpfer, N., Nedoluha, G. E., Yushkov, V., Khaykin, S., Kivi, R., and Vomel, H.: Middle Atmospheric Water Vapour Radiometer - MIAWARA: validation and first results of the LAUTLOS/WAVVAP campaign, J. Geophys. Res., 110, D13306, doi:10.1029/2004JD005543, 2005.

De Wachter, E., Haefele, A., Kämpfer, N., Ka, S., Lee, J. E., and Oh, J. J.: The Seoul Water Vapor Radiometer for the Middle Atmosphere: Calibration, Retrieval, and Validation, IEEE T. Geosci. Remote, 49, 1052-1062, doi:10.1109/TGRS.2010.2072932, 2011.

Feist, D. G., Geer, A. J., Müller, S., and Kämpfer, N.: Middle atmosphere water vapour and dynamical features in aircraft measurements and ecmwf analyses, Atmos. Chem. Phys., 7, 5291-5307, doi:10.5194/acp-7-5291-2007, 2007.

Flury, T., Müller, S. C., Hocke, K., and Kämpfer, N.: Water vapor transport in the lower mesosphere of the subtropics: a trajectory analysis, Atmos. Chem. Phys., 8, 7273-7280, doi:10.5194/acp8-7273-2008, 2008.

Froidevaux, L., Read, W. G., Lungu, T. A., Cofield, R. E., Fishbein, E. F., Flower, D. A., Jarnot, R. F., Ridenoure, B. P., Shippony, Z., Waters, J. W., Margitan, J. J., McDermid, I. S., Stachnik, R. A., Peckham, G. E., Braathen, G., Deshler, T., Fishman, J., Hofmann, D. J., and Oltmans, S. J.: Validation of UARS microwave limb sounder ozone measurements, J. Geophys. Res.Atmos., 101, 10017-10060, doi:10.1029/95JD02325, 1996.

Haefele, A., De Wachter, E., Hocke, K., Kämpfer, N., Nedoluha, G. E., Gomez, R. M., Eriksson, P., Forkman, P., Lambert, A., and Schwartz, M. J.: Validation of ground-based microwave radiometers at $22 \mathrm{GHz}$ for stratospheric and mesospheric water vapor, J. Geophys. Res.-Atmos., 114, D23305, doi:10.1029/2009JD011997, 2009.

Hocke, K., Kämpfer, N., Ruffieux, D., Froidevaux, L., Parrish, A., Boyd, I., von Clarmann, T., Steck, T., Timofeyev, Y. M., Polyakov, A. V., and Kyrölä, E.: Comparison and synergy of stratospheric ozone measurements by satellite limb sounders and the ground-based microwave radiometer SOMORA, Atmos. Chem. Phys., 7, 4117-4131, doi:10.5194/acp-7-4117-2007, 2007.

Holton, J. R. and Alexander, M. J.: The role of waves in the transport circulation of the middle atmosphere, American Geophysical Union, Washington D.C., 123, 9-5, doi:10.1029/GM123p0021, 2000.

Holton, J. R. and Gettelman, A.: Horizontal transport and the dehydration of the stratosphere, Geophys. Res. Lett., 28, 2799-2802, doi:10.1029/2001GL013148, 2001.

Julier, S. J. and Uhlmann, J. K.: A new extension of the Kalman filter to nonlinear systems, in: The 11th Int. Symp. on Aerospace/Defence Sensing, Simulation and Controls, vol. 3, 32, Orlando, FL, 1997. 
Kämpfer, N., Nedoluha, G., Haefele, A., and De Wachter, E.: Microwave Radiometry, vol. 10 of ISSI Scientific Report Series, Springer, New York, doi:10.1007/978-1-4614-3909-7, 2012.

Lambert, A., Read, W. G., Livesey, N. J., Santee, M. L., Manney, G. L., Froidevaux, L., Wu, D. L., Schwartz, M. J., Pumphrey, H. C., Jimenez, C., Nedoluha, G. E., Cofield, R. E., Cuddy, D. T., Daffer, W. H., Drouin, B. J., Fuller, R. A., Jarnot, R. F., Knosp, B. W., Pickett, H. M., Perun, V. S., Snyder, W. V., Stek, P. C., Thurstans, R. P., Wagner, P. A., Waters, J. W., Jucks, K. W., Toon, G. C., Stachnik, R. A., Bernath, P. F., Boone, C. D., Walker, K. A., Urban, J., Murtagh, D., Elkins, J. W., and Atlas, E.: Validation of the Aura Microwave Limb Sounder middle atmosphere water vapor and nitrous oxide measurements, J. Geophys. Res.-Atmos., 112, D24S36, doi:10.1029/2007JD008724, 2007.

Liu, G., Tarasick, D. W., Fioletov, V. E., Sioris, C. E., and Rochon, Y. J.: Ozone correlation lengths and measurement uncertainties from analysis of historical ozonesonde data in North America and Europe, J. Geophys. Res.-Atmos., 114, D04112, doi:10.1029/2008JD010576, 2009.

Liu, H.-L., Roble, R. G., Taylor, M. J., and Pendleton, W. R.: Mesospheric planetary waves at Northern Hemisphere fall equinox, Geophys. Res. Lett., 28, 1903-1906, doi:10.1029/2000GL012689, 2001.

Liu, J., Tarasick, D. W., Fioletov, V. E., McLinden, C., Zhao, T., Gong, S., Sioris, C., Jin, J. J., Liu, G., and Moeini, O.: A global ozone climatology from ozone soundings via trajectory mapping: a stratospheric perspective, Atmos. Chem. Phys., 13, 1144111464, doi:10.5194/acp-13-11441-2013, 2013.

Livesey, N. J., Read, W. G., Froidevaux, L., Lambert, A., Manney, G. L., Pumphrey, H. C., Santee, M. L., Schwartz, M. J., Wang, S., Coeld, R. I., Cuddy, D. T., Fuller, R. A., Jarnot, R. F., Jiang, J. H., Knosp, B. W., Stek, P. C., Wagner, P. A., and Wu, D. L.: Version 3.3 and 3.4 Level 2 data quality and description document, Tech. rep., Jet Propulsion Laboratory, California Institute of Technology, 2011.

Monge-Sanz, B. M., Chipperfield, M. P., Simmons, A. J., and Uppala, S. M.: Mean age of air and transport in a CTM: comparison of different ECMWF analyses, Geophys. Res. Lett., 34, L04801, doi:10.1029/2006GL028515, 2007.

Morris, G. A.: A demonstration and evaluation of trajectory mapping, PhD thesis, Rice University, 1994.

Morris, G. A., Schoeberl, M. R., Sparling, L. C., Newman, P. A., Lait, L. R., Elson, L., Walters, J., Suttie, R. A., Roche, A., Kumer, J., and Russel, J. M.: Trajectory mapping and applications to data from the Upper Atmosphere Research Satellite, J. Geophys. Res., 100, 16491-16505, doi:10.1029/95JD01072, 1995.

Morris, G. A., Gleason, J. F., Ziemke, J., and Schoeberl, M. R.: Trajectory mapping: A tool for validation of trace gas observations, J. Geophys. Res., 105, 17875-17894, doi:10.1029/1999JD901118, 2000.

Mote, P. W., Rosenlof, K. H., McIntyre, M. E., Carr, E. S., Gille, J. C., Holton, J. R., Kinnersley, J. S., Pumphrey, H. C., Russell, J. M., and Waters, J. W.: An atmospheric tape recorder: the imprint of tropical tropopause temperatures on stratospheric water vapor, J. Geophys. Res.-Atmos., 101, 39894006, doi:10.1029/95JD03422, 1996.

Nedoluha, G. E., Gomez, R. M., Hicks, B. C., Bevilacqua, R. M., Russell, J. M., Connor, B. J., and Lambert, A.: A comparison of middle atmospheric water vapor as measured by WVMS, EOS-
MLS, and HALOE, J. Geophys. Res.-Atmos., 112, D24S39, doi:10.1029/2007JD008757, 2007.

Nedoluha, G. E., Gomez, R. M., Hicks, B. C., Wrotny, J. E., Boone, C., and Lambert, A.: Water vapor measurements in the mesosphere from Mauna Loa over solar cycle 23, J. Geophys. Res.Atmos., 114, D23303, doi:10.1029/2009JD012504, 2009.

Nedoluha, G. E., Gomez, R. M., Hicks, B. C., Helmboldt, J., Bevilacqua, R. M., and Lambert, A.: Ground-based microwave measurements of water vapor from the midstratosphere to the mesosphere, J. Geophys. Res.-Atmos., 116, D02309, doi:10.1029/2010JD014728, 2011.

Nedoluha, G. E., Gomez, R. M., Neal, H., Lambert, A., Hurst, D., Boone, C., and Stiller, G.: Validation of long-term measurements of water vapor from the midstratosphere to the mesosphere at two Network for the Detection of Atmospheric Composition Change sites, J. Geophys. Res.-Atmos., 118, 934-942, doi:10.1029/2012JD018900, 2013.

Palm, M., v. Savigny, C., Warneke, T., Velazco, V., Notholt, J., Künzi, K., Burrows, J., and Schrems, O.: Intercomparison of $\mathrm{O}_{3}$ profiles observed by SCIAMACHY and ground based microwave instruments, Atmos. Chem. Phys., 5, 2091-2098, doi:10.5194/acp-5-2091-2005, 2005.

Paparella, F., Babiano, A., Basdevant, C., Provenzale, A., and Tanga, P.: A Lagrangian study of the Antarctic polar vortex, J. Geophys. Res.-Atmos., 102, 6765-6773, doi:10.1029/96JD03377, 1997.

Petterssen, S.: Weather analysis and forecasting, McGraw-Hill Book Company, New York, 221-223, 1940.

Rabier, F., Järvinen, H., Klinker, E., Mahfouf, J.-F., and Simmons, A.: The ecmwf operational implementation of fourdimensional variational assimilation. I: Experimental results with simplified physics, Q. J. Roy. Meteor. Soc., 126, 1143-1170, doi:10.1002/qj.49712656417, 2000.

Reinsel, G., Box, G., and Jenkins, G.: Time Series Analysis: Forecasting and Control, Third Edn., Prentice-Hall, Englewood Cliffs, 1994.

Revercomb, H. E., Buijs, H., Howell, H. B., LaPorte, D. D., Smith, W. L., and Sromovsky, L. A.: Radiometric calibration of IR Fourier transform spectrometers: solution to a problem with the High-Resolution Interferometer Sounder, Appl. Optics, 27, 3210-3218, doi:10.1364/AO.27.003210, 1988.

Rodgers, C. D.: Inverse Methods for Atmospheric Sounding: Theory and Practice, vol. 2, World Scientific, Singapore, 2000.

Rüfenacht, R., Murk, A., Kämpfer, N., Eriksson, P., and Buehler, S. A.: Middle-atmospheric zonal and meridional wind profiles from polar, tropical and midlatitudes with the ground-based microwave Doppler wind radiometer WIRA, Atmos. Meas. Tech., 7, 4491-4505, doi:10.5194/amt-7-4491-2014, 2014.

Scheiben, D., Straub, C., Hocke, K., Forkman, P., and Kämpfer, N.: Observations of middle atmospheric $\mathrm{H}_{2} \mathrm{O}$ and $\mathrm{O}_{3}$ during the 2010 major sudden stratospheric warming by a network of microwave radiometers, Atmos. Chem. Phys., 12, 7753-7765, doi:10.5194/acp-12-7753-2012, 2012.

Schoeberl, M. R.: Stratospheric warmings: observations and theory, Rev. Geophys., 16, 521-538, doi:10.1029/RG016i004p00521, 1978.

Schoeberl, M. R. and Sparling, L. C.: Trajectory modelling, in: Diagnostic Tools in Atmospheric Physics, edited by: Fiocco, G. and Visconti, G., vol. 1, IOS Press, p. 289, 1995. 
Stohl, A. and Seibert, P.: Accuracy of trajectories as determined from the conservation of meteorological tracers, Q. J. Roy. Meteor. Soc., 124, 1465-1484, doi:10.1002/qj.49712454907, 1998.

Stohl, A., Wotawa, G., Seibert, P., and Kromp-Kolb, H.: Interpolation errors in wind fields as a function of spatial and temporal resolution and their impact on different types of kinematic trajectories, J. Appl. Meteorol., 34, 2149-2165, doi:10.1175/15200450(1995)034<2149:IEIWFA>2.0.CO;2, 1995.

Straub, C., Murk, A., and Kämpfer, N.: MIAWARA-C, a new ground based water vapor radiometer for measurement campaigns, Atmos. Meas. Tech., 3, 1271-1285, doi:10.5194/amt-31271-2010, 2010.

Sutton, R. T., Maclean, H., Swinbank, R., O’Neill, A., and Taylor, F. W.: High-resolution stratospheric tracer fields estimated from satellite observations using Lagrangian trajectory calculations, J. Atmos. Sci., 51, 2995-3005, doi:10.1175/15200469(1994)051<2995:HRSTFE>2.0.CO;2, 1994.
Tschanz, B., Straub, C., Scheiben, D., Walker, K. A., Stiller, G. P., and Kämpfer, N.: Validation of middle-atmospheric campaignbased water vapour measured by the ground-based microwave radiometer MIAWARA-C, Atmos. Meas. Tech., 6, 1725-1745, doi:10.5194/amt-6-1725-2013, 2013.

Wang, P. K.: Moisture plumes above thunderstorm anvils and their contributions to cross-tropopause transport of water vapor in midlatitudes, J. Geophys. Res.-Atmos., 108, 4194, doi:10.1029/2002JD002581, 2003.

Wernli, H. and Davies, H. C.: A Lagrangian-based analysis of extratropical cyclones. I: The method and some applications, Q. J. Roy. Meteor. Soc., 123, 467-489, doi:10.1002/qj.49712353811, 1997. 